\title{
An Inductively Coupled Plasma-Time-of-Flight Mass Spectrometer for Elemental Analysis. Part III: Analytical Performance
}

\author{
D. P. Myers, G. Li, P. P. Mahoney, and G. M. Hieftje \\ Department of Chemistry, Indiana University, Bloomington, Indiana, USA
}

\begin{abstract}
A time-of-flight mass spectrometer (TOFMS) was evaluated as a mass analyzer for inductively coupled plasma mass spectrometry (ICP-MS). The long-term drift of signals was in the range of 7-8\% relative standard deviation, whereas the short-term precision was between 5 and $20 \%$, somewhat worse than is typically reported for commercial ICP-MS instruments (5\%). However, precision can be improved considerably in the TOFMS by ratioing isotopic peaks or through internal standardization, a consequence of its ability to extract all measured ions simultaneously from the inductively coupled plasma. This feature was demonstrated by monitoring the ${ }^{206} \mathrm{~Pb} /{ }^{208} \mathrm{~Pb}$ ratio with boxcar averagers. In this ratioing mode, precision was improved to approximately $0.5 \%$. Detection limits were measured with two alternative signal processing systems: (1) discriminator-gated integration and (2) integration of digitized spectra. Both methods improved the signal-to-noise ratio by a factor of from 10 to 100 , although detection limits were still 1-2 orders of magnitude poorer for most elements than from the best commercial ICP-MS instruments. The dynamic range of the discriminator-gated integration system is over 4 orders of magnitude, but can be extended to $10^{6}$ with planned increases in primary ion-beam current, which is currently 10-100 times lower than is found in other instruments. Virtually simultaneous multielement and multiisotope analysis is possible for masses from ${ }^{7} \mathrm{Li}$ to ${ }^{209} \mathrm{Bi}$ with minimal mass bias and detection limits on the 0.4-2-ppb level. (J Am Soc Mass Spectrom 1995, 6, 411-420)
\end{abstract}

$\mathrm{P}$ lasma source mass spectrometry that uses quadrupole mass analyzers has evolved into an effective technique for elemental analysis. The dominant plasma sources have been the inductively coupled plasma and the glow discharge, which are employed for liquid and solid samples, respectively. Different mass analyzers have been considered recently by several groups as alternatives to the traditional quadrupole instruments. These analyzers include double-focusing sector-field instruments that use the Mattauch-Herzog geometry [1-3], ion-trap mass spectrometers [4-6], Fourier-transform ion cyclotron resonance (FTICR) instruments $[7,8]$, and time-of-flight mass spectrometers (TOFMS) [9-13].

Goals in the utilization of these mass analyzers are to match or exceed the sensitivity, but to overcome some of the shortcomings of quadrupole mass filters. Two major drawbacks of the quadrupole are its need to detect isotopic peaks sequentially and its limited resolution. One Mattauch-Herzog design overcomes the first of these limitations by focusing ions onto an array detector to enable the simultaneous measurement of most of the elemental mass range [1-3]. However, the resolving power has been found to be less than unity at higher masses and detection limits are

Address reprint requests to Dr. Gary $M$. Hieftje, Department of Chemistry, Indiana University, Bloomington, IN 47405. only at the parts-per-billion level [1]. Ion-trap mass spectrometers have been coupled to both inductively coupled plasmas [4] and glow discharges $[5,6]$ with some success, but are still at a relatively early stage of development. An ion-trap-TOFMS combination also has been used with an atmospheric-pressure glow discharge [14]. FTICR instruments offer high enough resolving power to overcome isobaric interferences between atomic and polyatomic ions, which are especially troublesome with a glow-discharge source $[7,8]$. However, FTICR systems often are limited by their total ion capacity of roughly $10^{6}$ ions.

Work in our laboratory and in that of one other group has focused on coupling a time-of-flight mass spectrometer to an inductively coupled plasma [10, 11]. In addition, we have attached a radiofrequency glow discharge to the prototype TOFMS and found the results promising [13]. Falk et al. [12] have combined electrothermal vaporization with electron-impact ionization as an atomic ion source for TOFMS. King et al. [15] also have investigated a glow-discharge-TOFMS, and other investigators have used alternative radiofrequency-powered plasmas [16]. The present paper describes the analytical performance of an inductively coupled plasma-time-of-flight mass spectrometer (ICP-TOFMS) that has been improved considerably over an earlier system [17] through the incorporation of a new vacuum chamber and modified ion optics. 
The instrument shows promise to be competitive with quadrupole instruments in terms of sensitivity and simplicity, but offers the additional advantages of simultaneous ion extraction, rapid spectral generation, and efficient ion transmission [10].

\section{Experimental}

\section{Instrument Conditions}

The ICP-TOFMS instrument has been described previously $[10,13,17]$. In the present studies the TOFMS was operated in both linear and reflecting modes. The reflectron detector is a $40-\mathrm{mm}$ chevron microchannel plate (Galileo Electro-Optics, Sturbridge, MA) that has an extended dynamic range. The ion optics of the instrument are identical to those described in our previous publication [17]. The ICP-TOFMS was operated in a pulsed-ion-injection mode [17] except when multielement analysis was performed with a ramped steering plate. In this latter case the ion optics were operated in the continuous ion-injection mode [17]. The ramped steering plate was used to overcome the mass-dependent trajectory of ions in the orthogonal flight tube and was implemented with a linear voltage ramp with a ramp rate of $-15 \mathrm{~V} / \mu \mathrm{s}$ and a delay time of 2-4 $\mu \mathrm{s}$ (depending on the mass range being detected) after the repeller pulse is applied to the steering plate $\left(Y_{2}\right)[17]$. The continuous ion-injection mode was utilized because, as will be described later, the optic settings are not as mass dependent as they are in the pulsed-ion-injection mode. Thus, the continuous ion-injection mode is more conducive to multielement analysis.

Sample introduction was accomplished with an ultrasonic nebulizer followed by desolvation (see [17] for conditions). All sample solutions were prepared by dilution of purchased stock solutions (1000 ppm, Johnson-Matthey, Ward Hill, MA) or from prepared stock solutions [18].

\section{Detection Electronics}

Several electronic readout systems were used to evaluate the analytical performance of the modified ICPTOFMS. A discriminator-gated integrating detection system was employed for detection-limit measurements. This system has been described previously [19]. The analog output of the gated integrator was read by the analog-to-digital converter of a National Instruments (Austin, TX) NB-MIO-16XL board installed in a Macintosh Quadra 950 computer (Apple Computer, Inc., Cupertino, CA). The data acquisition board was programmed with LabVIEW II software (National Instruments). The gated integrator overflow and reset lines were connected to two digital I/O lines on the NB-MIO-16XL board so the integrators could be reset at specified integration times and /or after an overflow had occurred.

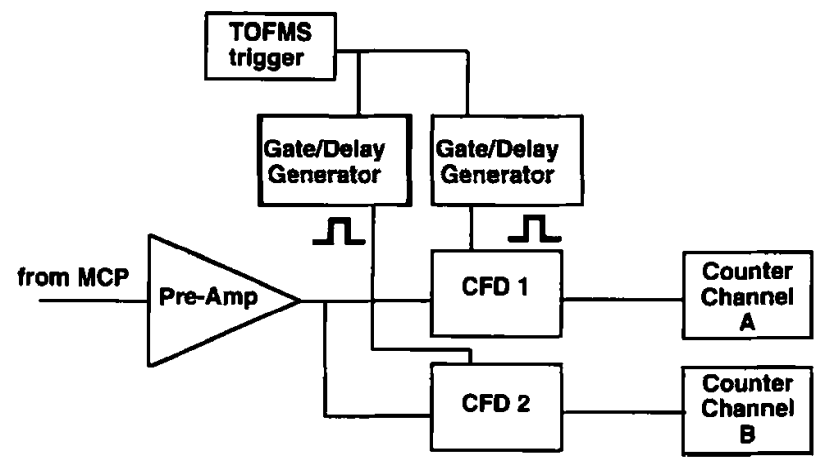

Figure 1. Layout of the gated ion-counting detection system.

A system similar to an integrating transient recorder also was used to evaluate detection limits by collecting successive averaged spectra from a Tektronix (Beaverton, OR) TDS 520 digital oscilloscope via a generalpurpose interface bus interface. These spectra were then summed to improve the signal-to-noise ratio and detection limits. The collection and integration of spectra were accomplished on a Macintosh Quadra 950 with LabVIEW II software and a NB-DMA2000 board (National Instruments).

For measurements of signal stability, a boxcar averager (Stanford Research Systems, Stanford, CA, model SR250) was utilized. The signals were sent directly from the microchannel plate (MCP) detector/preamplifier to the averagers, which were set to average a specified number of boxcar samples. The values then were read out through the analog-to-digital converter in the Quadra 950 computer.

In addition to the foregoing electronics, a counting method was used to estimate the throughput of the primary ion beam and to evaluate signal stability. The setup for the counting method is shown in Figure 1. Two counters, an Ortec (Oak Ridge, TN) model 449 and a Hewlett-Packard (Avondale, PA) model 5302A $(50 \mathrm{MHz})$ universal counter, were employed to count the nuclear instrumentation module (NIM) pulses from a constant-fraction discriminator (CFD; model TC454, Oxford Instruments, Oak Ridge, TN). The CFD produces NIM pulses of constant width and height each time a signal pulse above a set voltage threshold is received at its input.

\section{Results and Discussion}

\section{Signal Stability and Precision}

The medium- and long-term drift of the signals in the ICP-TOFMS instrument was investigated with both the counting system depicted in Figure 1 and with the boxcar averagers. The signal from a 10-ppm Co solution was monitored beginning $3 \mathrm{~min}$ after the $\mathrm{ICP}$ TOFMS was started. The Co signal was averaged for 1000 input ion pulses $(141 \mathrm{~ms}$ at $7.1-\mathrm{kHz}$ repetition rate) and the averaged values were plotted over a 30-min period (cf. Figure 2). The relative standard 


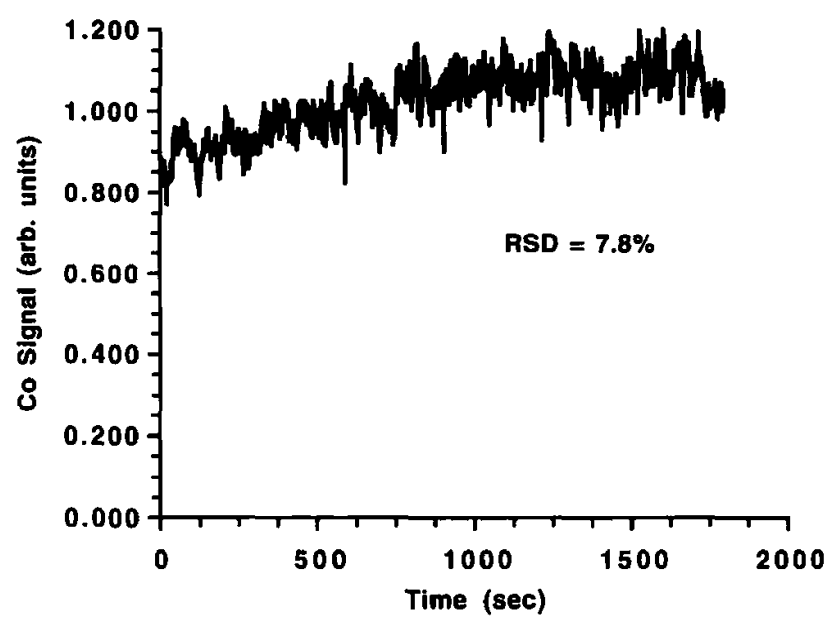

Figure 2. Variation in Co signal ( $10 \mathrm{ppm}$ ) beginning $3 \mathrm{~min}$ after start-up of the ICP-TOFMS. The signal is monitored by boxcar averagers. Each plotted point is the average of 1000 boxcar samples, which corresponds to a 141-ms measurement time at $7.1-\mathrm{kHz}$ repetition rate.

deviation (RSD) of the trace $(7.8 \%)$ is due principally to the clear upward drift. The effective warm-up time of the ICP-TOFMS is about $1 \mathrm{~h}$.

After a 1-hour warm-up, the short-term precision (measured over a 5-min interval) of the signals from six elements (each $1 \mathrm{ppm}$ ) was evaluated with the counter shown in Figure 1; the recorded traces are displayed in Figure $3 a-f$. The integration time of the counter for the individual points plotted in Figure 3 is $30 \mathrm{~ms}$. The downward spikes in the $\mathrm{Cs}$ and $\mathrm{Pb}$ traces (Figure $3 e$ and $f$ ) originate from instabilities in the plasma or sample-introduction system. Nevertheless, the resulting precision, which ranges from $4.4 \%$ RSD for $\mathrm{Pb}$ to $24 \%$ for $\mathrm{Zr}$, is comparable to literature values if the signal-integration interval is taken into account. For example, Thompson and Houk [20] report values of $5-8 \%$ over $1 \mathrm{~h}$ with a 0.5 -s integration time on a quadrupole instrument coupled to a $27.12 \mathrm{MHz}$ plasma. Vickers et al. [21] reported precision from a $40-\mathrm{MHz}$ instrument of $12.8 \%$ over $30 \mathrm{~min}$ with a $10-\mathrm{s}$ integration time. The long-term drift in Figure 2 also exhibits better precision than Vickers et al. reported with a $40-\mathrm{MHz}$ plasma.

In the ICP-TOFMS, all ions are extracted simultaneously from the primary ion beam. Therefore, ratioing the signals from two species should partially overcome drift or other forms of multiplicative noise that originate in the ICP, sample-introduction equipment, or ion-sampling process. Because such sources of noise are often dominant, the ratioing mode should offer excellent precision. Obviously, any drift or noise that arises in the TOFMS or detection electronics will not be correlated in the two monitored signals, and the ratioing will worsen precision if the noise sources are dominant.

The success of ratioing techniques or internal standardization is dependent entirely on the proper choice of an internal standard or ratio reference. Previous work has shown that the reference should be similar in mass and ionization energy to the analyte or analytes of interest [20, 22]. Obviously, the optimal internal standard would be an isotope of the element of interest. However, this is not possible with monoisotopic elements and might be prohibitively expensive for other elements for which low-cost isotopically enriched standards are not available.

To illustrate the behavior of a suitable internal standard, the time-dependent signals from two $\mathrm{Pb}$ isotopes (1-ppm total $\mathrm{Pb}$ concentration) are plotted in Figure 4. Each point in Figure 4 is the result of 300 averages, which is a $42-\mathrm{ms}$ measurement time. Also, these data were obtained after only $30 \mathrm{~min}$ of warm-up time, so variation and drift would be especially apparent. The precision of both traces is low (17\%) but identical. More importantly, the signals track each other well and ratioing yields a precision of 1.9\% RSD.

Figure 4 illustrates the power of internal standardization with the ultimate standard-an isotope of the element of interest. However, when an isotope is not available, an element that has similar properties to the analyte is recommended [20,22]. By using the boxcar averagers in the same manner as with the $\mathrm{Pb}$ isotopes (Figure 4), we investigated several signals for possible use as internal-standard pairs. Figure $5 a$ shows the signals for ${ }^{90} \mathrm{Zr}$ and ${ }^{80} \mathrm{Ar}_{2}$ as a function of time. Not surprisingly, the two signals do not track each other well over the 5-min observation period and the precision of the ratio $(10 \%)$ is little better than that of $\mathrm{Zr}$ by itself $(12 \%)$. The fact that the ${ }^{90} \mathrm{Zr}$ signal is less stable than that of $\mathrm{Ar}_{2}$ suggests that sample-introduction noise might be dominant. Also, Figure 5a corroborates the assertions of other workers that polyatomic ions are not viable internal standards for analyte ions because they arise from a different mechanism [22].

Next we investigated two elements of different ionization energy and mass and their ability to track each other. Figure $5 b$ shows ${ }^{208} \mathrm{~Pb}(7.416-\mathrm{eV})$ and ${ }^{7} \mathrm{Li}$ (5.392$\mathrm{eV)}$ signals as a function of time. Because the signals are not well correlated, the precision of the ratio $6.7 \%$ RSD) is poorer than that of either individual trace. The difference in mass and ionization energy is certainly the reason [22]. However, if the ${ }^{7} \mathrm{Li}$ signal is ratioed to ${ }^{90} \mathrm{Zr}$, which is closer in ionization energy $(6.84 \mathrm{eV})$ [23] and mass, we would expect the ratio precision to be better. Indeed, as Figure $5 \mathrm{c}$ shows, the ${ }^{7} \mathrm{Li}$ and ${ }^{90} \mathrm{Zr}$ signals track each other remarkably well and the ratioing process increases precision to $4.8 \%$ RSD.

Although the precision of the ratio shown in Figure $5 \mathrm{c}$ is promising, it is limited by a rather short signal-accumulation interval $(42 \mathrm{~ms})$. Increasing the number of averages or the effective measurement time can improve the precision considerably. Figure 6 shows how precision of the ${ }^{208} \mathrm{~Pb} /{ }^{206} \mathrm{~Pb}$ ratio improves as a function of the number of averages. The fitted curve ( $y=$ $\left.19.654 \times x^{-0.37259} R=0.99544\right)$ follows the expected $1 / N^{1 / 2}$ dependence ( $N=$ number of averages) up to 
a

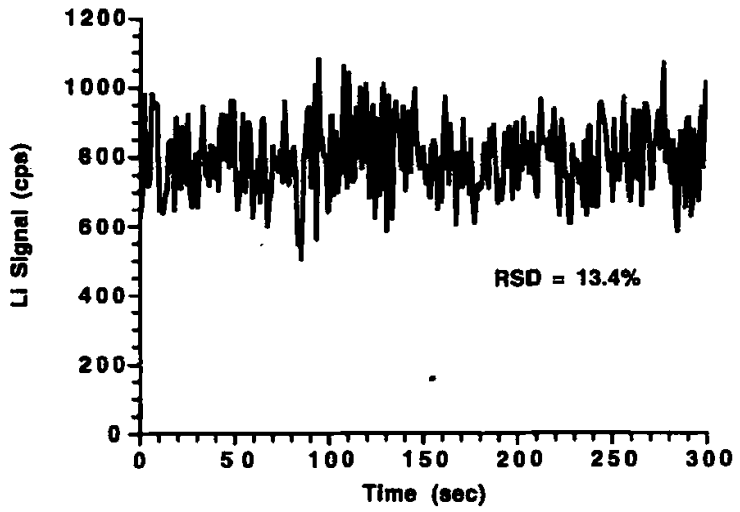

c

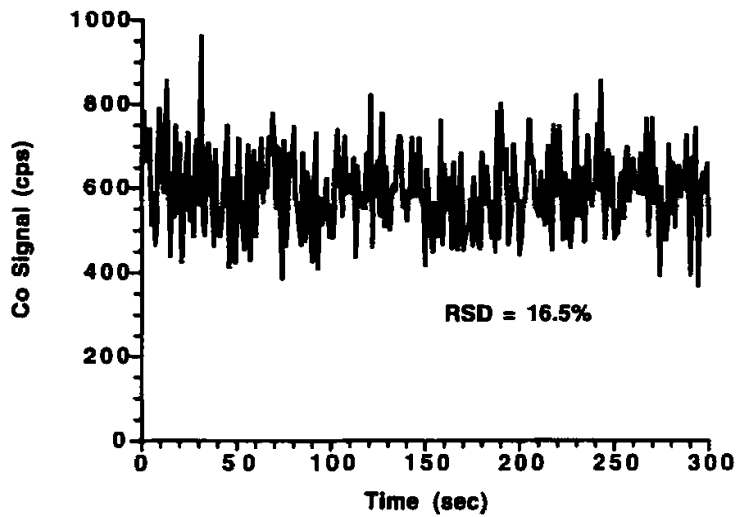

e

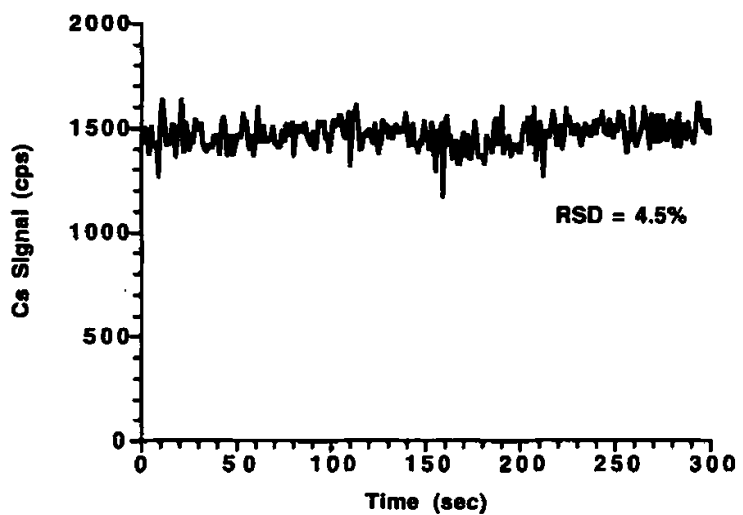

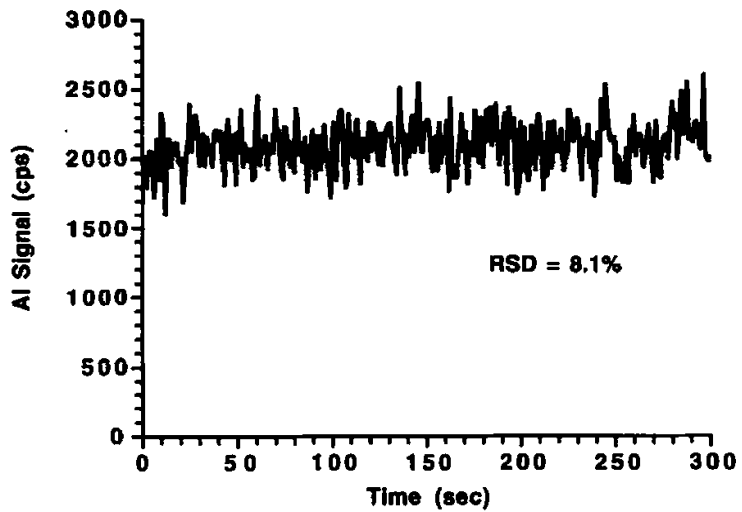

d

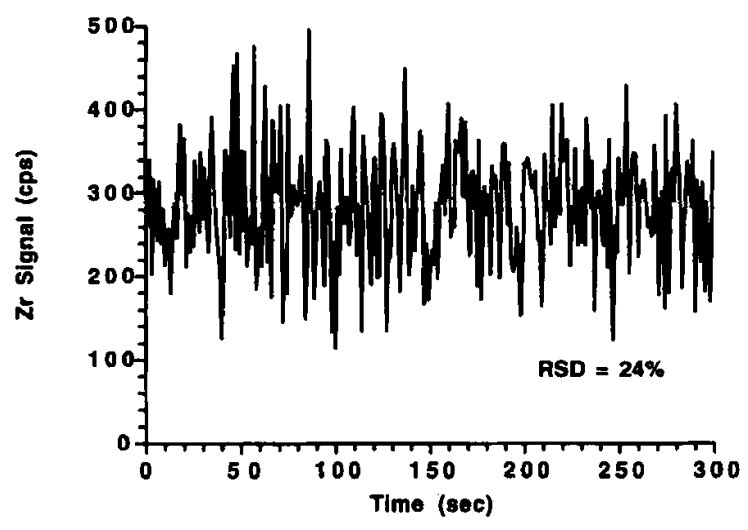

f

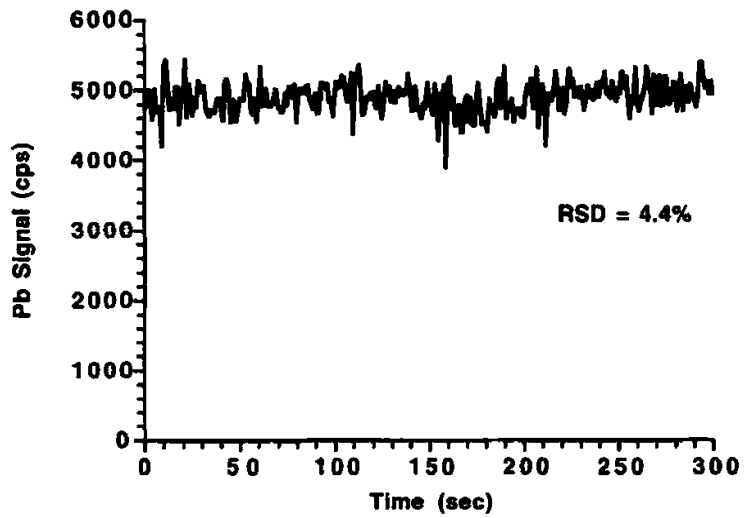

Figure 3. Temporal (5-min) variation in selected elemental signals. Each plot is on a different vertical scale and was recorded at the most abundant isotope of each element. Signals are from the output of the gated ion counters shown in Figure 1 and result from an integration time of $30 \mathrm{~ms}$. (a) 1-ppm Li; (b) 1-ppm Al; (c) 1-ppm Co; (d) 1-ppm $\mathrm{Zr}$; (e) 1-ppm Cs; (f) 1-ppm Pb.

approximately 10,000 averages $(1.4 \mathrm{sec})$, at which point the measurement precision is $0.57 \%$ RSD. The $10,000-$ averages setting is the limit of the SR250 boxcar averager; however, using these signal values and averaging every 10 points, an RSD of $0.46 \%$ is obtained. This value departs from the $1 / N^{1 / 2}$ behavior and might signal an approaching limit in precision improvement, induced either by the spectrometer or by the signalprocessing system.

\section{Detection Limits}

Detection limits in the ICP-TOFMS were measured both with the CFD-gated integrator [19] and by integration of successive averaged transients obtained from a digital oscilloscope. In addition, instrumental sensitivities for the linear and reflectron geometries were compared.

Before evaluation of the detection limits, it is instructive to compare the flux of the current input-ion beam to that reported for commercial instruments. In such instruments, the primary beam flux is typically $1 \times 10^{6}$ to $10^{7}$ ions $/ \mathrm{s} \mathrm{ppm}^{-1}$. The corresponding value for the current system can be estimated with the gated counting system. However, we must consider the time period during which the TOFMS actually measures the ions and must account for the transmission of the mass spectrometer.

The time required for the primary beam to fill the right-angle extraction zone is approximately $3.6 \mu \mathrm{s}$ 


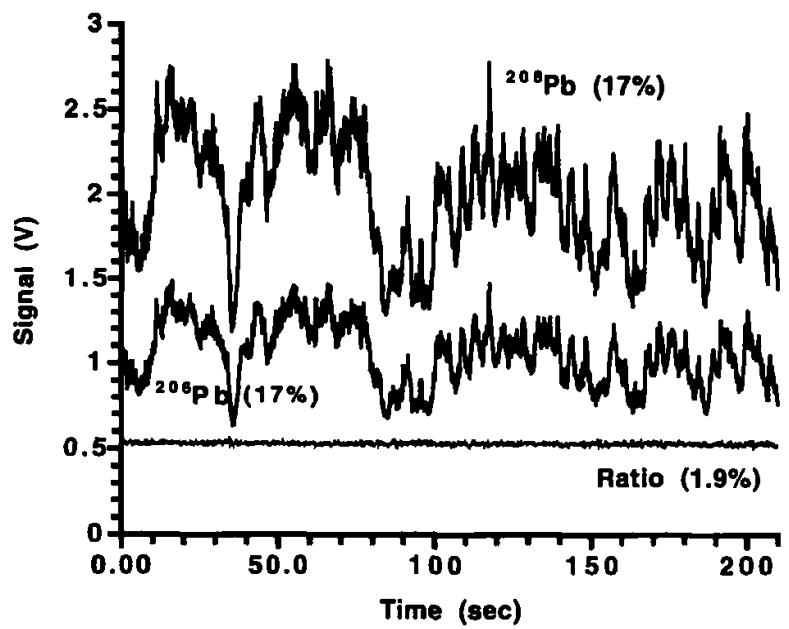

Figure 4. Signals for ${ }^{208} \mathrm{~Pb}$ and ${ }^{206} \mathrm{~Pb}$ and their ratio recorded over a period of $4 \mathrm{~min}$. Each datum point is the output from a single channel of the boxcar averager system in the 300-averages mode and corresponds to a measurement time of $42 \mathrm{~ms}$.

(velocity $=7.1 \times 10^{3} \mathrm{~m} / \mathrm{s}$ for Ar and 2.54-cm extraction length [10]). With the current repetition rate of the instrument limited to $7.1 \mathrm{kHz}$, the actual time during which the continuous beam is measured for $1 \mathrm{~s}$ of TOFMS operation is $25.6 \mathrm{~ms}$. This corresponds to a duty factor of approximately $3 \%$. We measure 2600 counts $/ \mathrm{s}$ with the gated counting system for a $100-\mathrm{ppb}$ solution of Cs, which implies a count rate of $1.0 \times 10^{5}$ counts $/ \mathrm{s}$ in the original continuous beam. When we take into account that the transmission of the TOFMS is roughly $20 \%$ [10], the actual count rate in the primary beam is probably around $5 \times 10^{5}$ counts/s, which is $10-100$ times lower than in the least sensitive commercial instruments. From this estimation, we would expect poorer detection limits for equivalent integration times than has been found with other instruments. However, it seems equally clear that it should be possible to improve the values by boosting primary beam current.

The first integration method that was tested employs the CFD-gated integrator used previously [19]. To measure signals with the CFD-gated integrator, the gate was aligned temporally to the mass of interest and the signal was read for five successive integration periods. Following collection of the signal, the blank was nebulized into the plasma for a 1- to 5-min period; then the background was collected in the same manner. Detection limits were determined by dividing the net signal (integrated signal minus integrated blank) by the standard deviation of the five blank measurements. For each element the detection limit was computed by determination of the signal-to-background noise ratio $\left(S / N_{b}\right)$ for a 100-ppb concentration and extrapolation to a concentration that corresponds to a $S / N_{\mathrm{b}}$ ratio equal to 3 .

Of course, this method assumes that the response from the CFD-gated integration system is linear between $100 \mathrm{ppb}$ and the detection limit. The linearity of
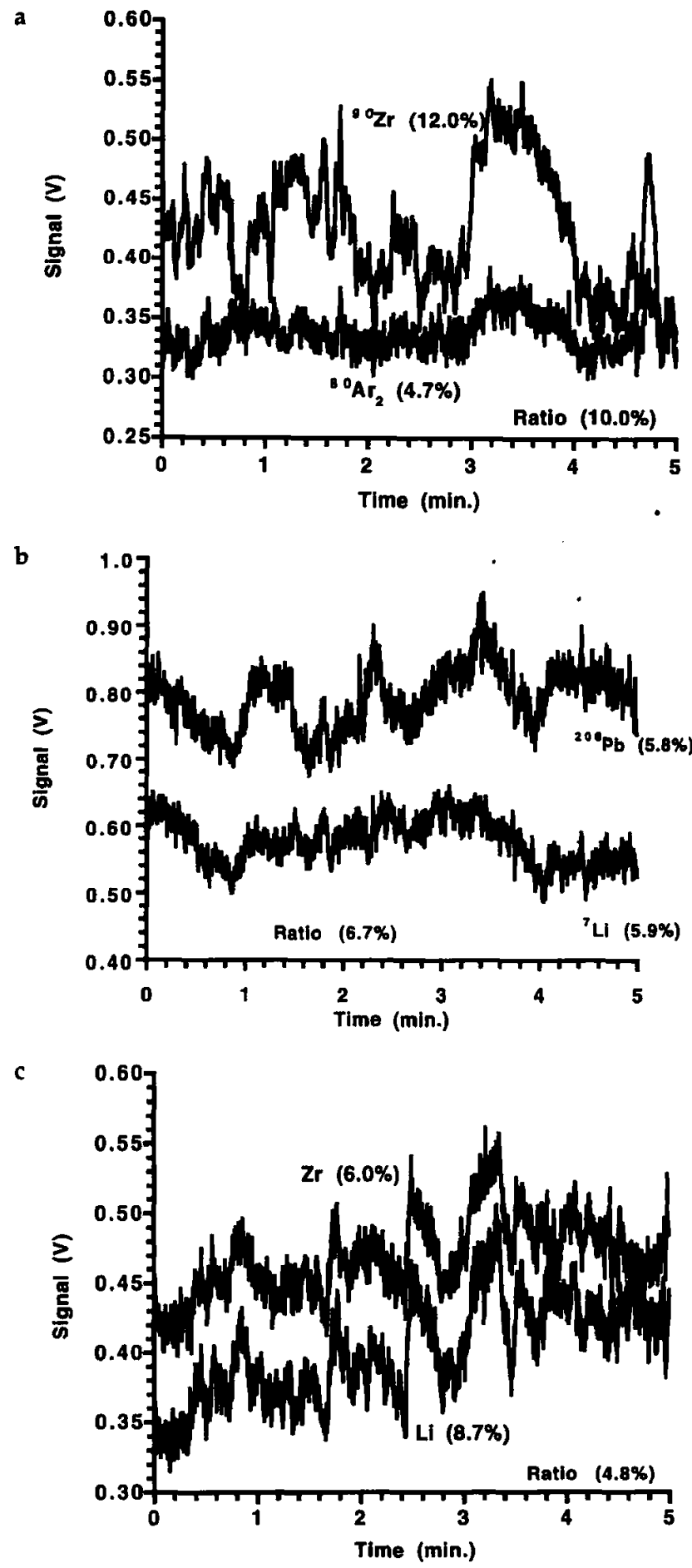

Figure 5. Simultaneous two-channel measurements with the boxcar averager system. Measurements that track each other well constitute good internal-standard pairs. Each datum point is from a measurement time of $42 \mathrm{~ms}$ (300 averages). Signals (a) for ${ }^{90} \mathrm{Zr}$ and ${ }^{80} \mathrm{Ar}_{2}$, (b) for ${ }^{208} \mathrm{~Pb}$ and ${ }^{7} \mathrm{Li}$, and (c) for ${ }^{90} \mathrm{Zr}$ and ${ }^{7} \mathrm{Li}$ as a function of time.

the CFD integration system as a function of concentration for the linear and reflectron TOFMS arrangements spans 4 to 5 orders of magnitude for most elements that were studied (see Figure $7 a$ and $b$, respectively). Also, all plots of $S / N_{b}$ versus concentration exhibit 


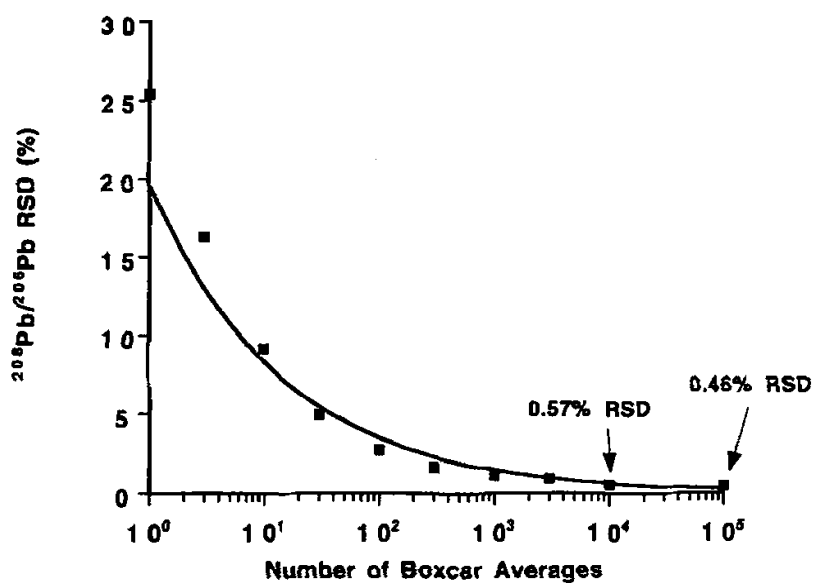

Figure 6. Improvement in relative standard deviation (RSD) for the ${ }^{208} \mathrm{~Pb} /{ }^{206} \mathrm{~Pb}$ ratio with number of boxcar averages. The value at 100,000 averages is obtained from software averaging of ten 10,000-value averages. The curve is the fitted function $y=$ $19.654 \times x^{-0.37259} R=0.99544$.

correlation coefficients $(R)$ near unity. The $y$-intercept of every regression line in Figure 7 is within 1 standard deviation of zero, which indicates that the extrapolation to the detection limit is valid. Overall, working curve fits are worse in the reflectron TOFMS (Figure $\mathrm{7b}$ ), especially for $\mathrm{Li}$ and $\mathrm{Mn}$, which may be caused by higher noise levels at these masses or detection system instability.

In the working curve for the linear TOFMS (Figure $7 a)$ one can observe that the sensitivity $\left(S / N_{b}\right.$ for a given concentration) is almost 1 order of magnitude higher for the heaviest element $(\mathrm{Bi})$ than for the lighter elements. In the reflectron configuration (Figure $7 \mathrm{~b}$ ), the sensitivity of $\mathrm{Cs}$ and $\mathrm{Bi}$ are within the same order of magnitude, whereas $\mathrm{Li}$ is higher than that of $\mathrm{Mn}$. Possible reasons for these observed sensitivity differences will be explained later. Table 1 lists detection limits in parts per billion and nanomoles per liter measured with the CFD-gated integrator for nine elements that span much of the atomic mass range.

Promising detection limits are observed for heavier elements $(\mathrm{Cs}, \mathrm{Pb}$, and $\mathrm{Bi})$. In addition, detection limits obtained in the reflectron configuration are better (except $\mathrm{Mn}$ ) than those measured with the linear instrument. Possible reasons include lower noise levels in the reflectron [17]. However, the reflectron detector is a newer MCP with extended dynamic range. Note also that long integration times $(60 \mathrm{~s})$ were required to achieve good detection limits with the CFD-gated integrator, mainly because of the signal losses from splitting and delaying for discrimination purposes [19].

The second method for determination of detection limits utilizes software summation of successive averaged transients collected with a digital oscilloscope. Although the accumulation rate of spectra is slower than the $7.1-\mathrm{kHz}$ frequency capability of the TOFMS, we can infer the ultimate detection capabilities of such a scheme in ICP-TOFMS. This method was applied only to the reflectron TOFMS.

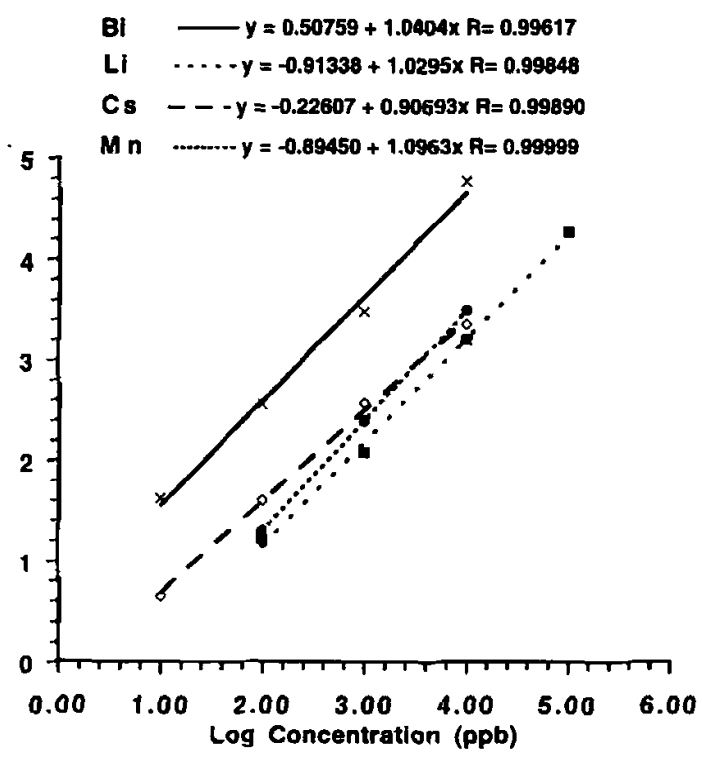

b

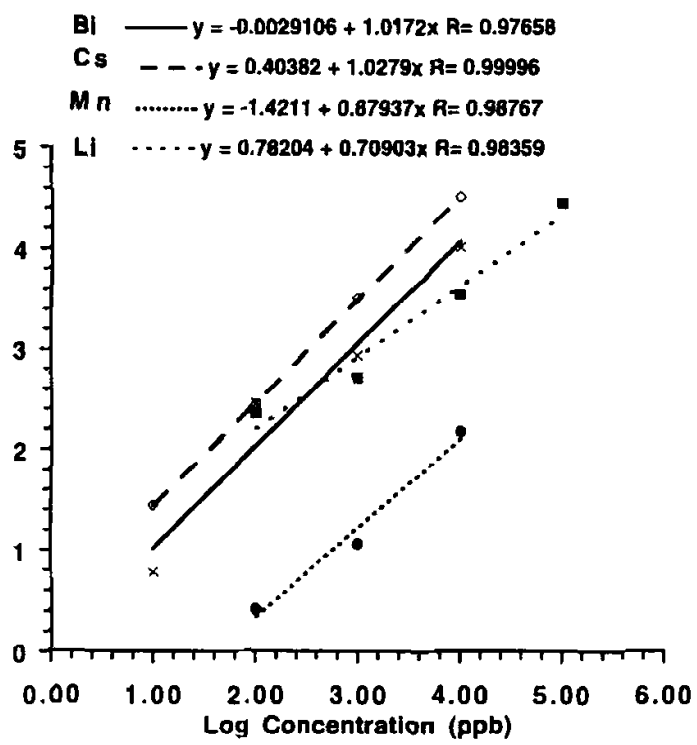

Figure 7. Fitted working curves from the CFD-gated integration system based on the log of signal-to-background noise ratio for various elements versus the log of concentration (CFD threshold $=-50 \mathrm{mV}$, integration time $=60 \mathrm{~s}$ ). (a) Linear TOFMS; (b) reflectron TOFMS.

As expected, the best $S / N_{\mathrm{b}}$ ratio is obtained when a large number of spectra are summed or averaged. In particular, high $S / N_{\mathrm{b}}$ ratios were obtained for the summation of 1000 spectra, each of which was the average of 100 shots. We limited the number of spectra to this value because the true (laboratory) measurement time for acquisition was not yet excessive (roughly $10 \mathrm{~min}$ ). However, acquisition of 100,000 spectra corresponds to a real TOFMS measurement time of only $14 \mathrm{~s}$ at the current repetition rate of 7.1 $\mathrm{kHz}$. Detection limits were determined via an integration method similar to that outlined by previous workers [24]. Each peak was integrated over a constant number of points (between 9 and 13) and the background was determined by integration of the same 
Table 1. Detection Limits in the Linear and Reflectron ICP-TOFMS

\begin{tabular}{|c|c|c|c|c|c|c|c|c|c|}
\hline \multirow[b]{2}{*}{ Element } & \multicolumn{2}{|c|}{ Linear ${ }^{\circ}$} & \multicolumn{2}{|c|}{ Reflectron ${ }^{a}$} & \multicolumn{2}{|c|}{ Reflectron ${ }^{b}$} & \multicolumn{2}{|c|}{$\begin{array}{l}\text { Reflectron with } \\
\text { ramped Y2 plate }\end{array}$} & \multirow{2}{*}{$\begin{array}{c}\text { HP } 4500 \\
\text { ICP-MS } \\
\text { ppb }\end{array}$} \\
\hline & ppb & $\mathrm{nmol} / \mathrm{L}$ & ppb & $\mathrm{nmol} / \mathrm{L}$ & ppb & $\mathrm{nmol} / \mathrm{L}$ & ppb & $\mathrm{nmol} / \mathrm{L}$ & \\
\hline${ }^{7} \mathrm{Li}$ & 0.40 & 57 & 0.18 & 2.6 & 0.31 & 44 & 1.6 & 230 & $0.001-0.01$ \\
\hline${ }^{27} \mathrm{Al}$ & 3.4 & 130 & 0.63 & 23 & - & 一 & - & - & $<0.001$ \\
\hline${ }^{55} \mathrm{Mn}$ & 1.8 & 33 & 2.6 & 47 & 0.99 & 18 & 0.40 & 7.3 & $0.001-0.01$ \\
\hline${ }^{90} \mathrm{Zr}$ & 5.8 & 64 & 1.2 & 13 & - & - & - & - & $<0.001$ \\
\hline${ }^{103} \mathrm{Rh}$ & 0.8 & 7.8 & 0.29 & 2.8 & - & - & - & - & $<0.001$ \\
\hline${ }^{133} \mathrm{Cs}$ & 0.5 & 3.8 & 0.035 & 0.26 & 0.39 & 2.9 & 0.62 & 4.7 & $<0.001$ \\
\hline${ }^{184} W$ & 0.7 & 3.8 & 0.49 & 2.7 & - & 一 & - & - & $<0.001$ \\
\hline${ }^{208} \mathrm{~Pb}$ & 1.3 & 6.3 & 0.096 & 0.46 & - & - & $\longrightarrow$ & - & $<0.001$ \\
\hline${ }^{209} \mathrm{Bi}$ & 0.7 & 3.3 & 0.097 & 0.46 & 0.082 & 0.39 & 0.88 & 4.2 & $<0.001$ \\
\hline
\end{tabular}

${ }^{a}$ CFD-gated integrator (60-s integration: $4.26 \times 10^{6}$ pulses).

${ }^{\circ}$ Oscilloscope integration (14-s integration; 100,000 spectra).

10-s integration; clean room conditions (Hewlett-Packard HP 4500 ICP-MS product literature document, Hewlett-Packard, Avondale, PA, 1994).

number of points to the left or right of each peak where no mass-spectral peaks should exist. The net signal was then taken as the difference between signal and background levels. The noise on the background was computed as the standard deviation of the background points and multiplication by the square root of the number of points. The detection limit is calculated from the following equation [24]:

$$
\mathrm{DL}=[\text { concentration }](3 \sigma / S) n^{1 / 2}
$$

where $\sigma$ is the standard deviation of $n$ background points.

Detection limits obtained with this setup are very similar to those measured with the CFD-gated integrator (see Table 1); they range from 0.082 to $0.99 \mathrm{ppb}$. Heavier elements ( $\mathrm{Bi}$ and $\mathrm{Cs}$ ) exhibit the best detection limits; elements close to $\mathrm{Ar}$ are worse. The detection limit for Cs is 10 times worse than that observed with the CFD-gated integrator, possibly because of the long actual (laboratory) time that was required. Over this interval the signal for Cs could have drifted downward. In addition, the detection limits for $\mathrm{Mn}$ are better with oscilloscope integration, which suggests that the averaging process might reduce the high noise level seen at the flight time of $\mathrm{Mn}$.

In summary, both readout systems produce detection limits in the 40-ppt to $2.6-\mathrm{ppb}$ range and heavier elements exhibit the best values. The oscilloscope integration technique requires a shorter integration time to achieve the same detection limits as the CFD-gated integrator. These results suggest that an integrating transient recorder would be effective for readout in ICP-TOFMS. However, the CFD-gated integrator would be less expensive and could be expanded to any desired number of channels.

\section{Mass Bias in Inductively Coupled Plasma-Time-of-Flight Mass Spectrometry}

The detection limits in Table 1 are rather mass dependent and the heavier elements offer the best values. In addition, elements that are close in mass to argon exhibit poor sensitivity. Argon ions that impinge on the microchannel plate might reduce its sensitivity for $\mathrm{Mn}$ and elements with flight times shortly after argon. However, the detection limits also are worse for $\mathrm{Al}$, which is just lighter than Ar. The overall mass dependence seems to be worse in the reflectron configuration.

The mass dependence of detection limits might be a consequence of changes in either signal or noise levels across the mass range. Figure 8 shows a plot of integrated signals (100 ppb for each element) and integrated background noise as a function of ion mass for CFD-gated integration in the reflectron mode. Clearly, the background noise is of the same order of magnitude across the entire mass range, although there is slightly lower noise in the vicinity of ${ }^{209} \mathrm{Bi}$ and ${ }^{7} \mathrm{Li}$. As a result, the detection limit for $\mathrm{Li}$ is excellent despite the lower signal level of that ion. Similarly, the detection limit for Cs is the lowest of all tested elements because of its high signal level. The signal levels for ${ }^{55} \mathrm{Mn}$ and ${ }^{90} \mathrm{Zr}$ are lower than for all other tested elements, which is the major cause of their poor detection limits.

Figure 8 suggests that the major cause of poor detection limits for specific elements is a lower signal level. Many factors could be the cause of element-dependent signal levels. Obvious reasons are lower ionization efficiencies and abundance levels for some peaks, specifically ${ }^{90} \mathrm{Zr}$ and ${ }^{184} \mathrm{~W}$. However, spacecharge effects in the primary ion beam might explain the disparity between light and heavy elements, because the lighter ions would be preferentially lost under such conditions [25].

Another possible source of mass bias is the argon-ion deflection scheme employed in both the linear and reflectron modes. This process involves the application of a pulse to suitably positioned deflection plates at the time when $\mathrm{Ar}^{+}$ions pass by them; the intention is to avoid detector saturation and space-charge that the high $\mathrm{Ar}^{+}$flux could otherwise cause. However, any 


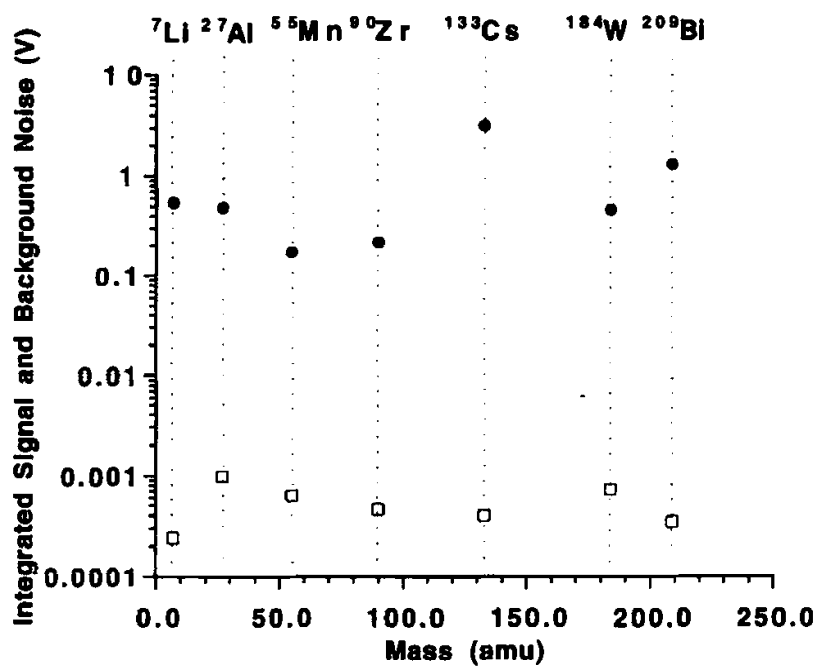

Figure 8. Plot of integrated signal and integrated background noise as a function of mass for the CFD-gated integration system in the reflectron TOFMS (each element $100 \mathrm{ppb}$ in solution). Integrated signal, ; background noise, $\square$.

inefficiency in the process might sacrifice transmission for ions at neighboring flight times. The argon-ion deflection system is more efficient in the reflectron TOFMS, because it uses second-order space focusing [26] to bunch the ions in the extraction zone. This bunched ion packet, with reduced time error, is then reflected to the detector surface by the reflectron. The argon ions therefore have a smaller time spread at the deflection plates than in the linear TOFMS and can be removed more selectively. In the reflectron, the noise levels are slightly higher near argon (see Figure 8), which may be caused by scattered argon ions from the deflection process. Further study is needed to verify the origin of these mass dependencies and to reduce them.

There is also a mass bias in the field for the steering plate of the instrument that is caused by the right-angle geometry and the initial velocity of ions extracted from the ICP [10]. To overcome the mass-dependent steering potential, a voltage ramp of adjustable delay and ramping time has been applied to the steering plate to steer ions of all masses to the detector. Figure 9 shows a diagram of the ramping system and its operating principle (see Experimental section for ramping details). Under conditions of continuous ion injection [17], the ramped steering plate was optimized first for a light element ( $\mathrm{Li}$ ) and then for a heavy element (Bi). Finally, the steering-plate ramp was applied and adjusted in amplitude, ramp rate, and temporal position to maximize all signals from a multielement solution (1-ppm Li, Mg, Mn, Cs, Bi). The results of this test are shown in Figure $10 \mathrm{a}-\mathrm{c}$. Clearly, the signals from the lighter elements ( $\mathrm{Li}$ and $\mathrm{Mg}$ ) are improved by ramping the steering plate (compare to Figure 10b). Also, the noise level in the spectrum obtained with the ramped plates (Figure 10c) is lower than that in the spectra optimized for individual elements (Figure 10a

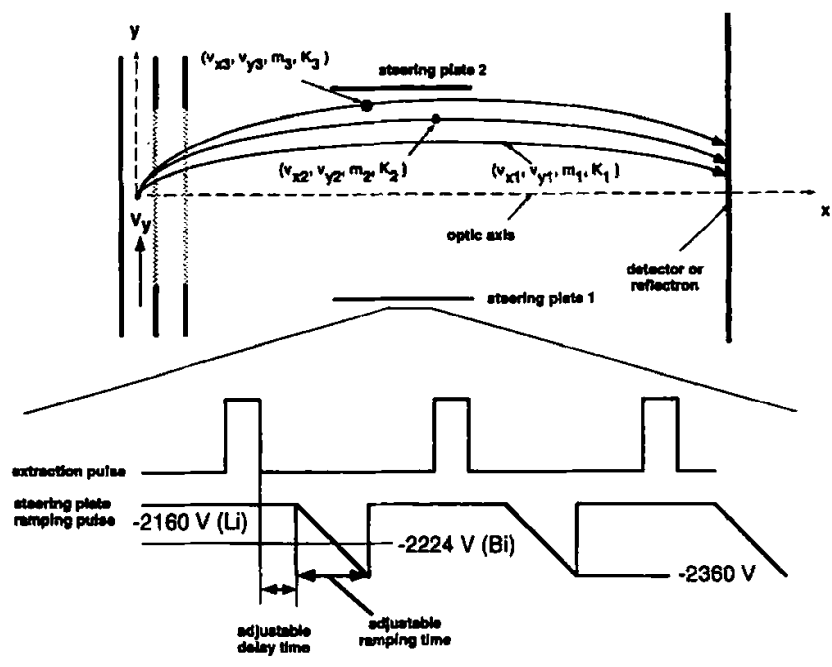

Figure 9. Diagram of the steering-plate ramping operation and principles in the ICP-TOFMS. $v_{y}$, ion velocity in $y$ dimension; $v_{x}$, ion velocity in $x$ dimension (flight tube axis); $m$, mass of the ion; $K$, kinetic energy of the ion.

and $b$ ). Noise levels always have been higher when lower steering-plate potentials are employed, which suggest that the scattered noise ions have lower energies than those that strike the detector directly. Figure 9 shows the initial and final potentials on the ramped steering plate, as well as the optimal potential for $\mathrm{Bi}$ ions. When ramp voltages above $-2224 \mathrm{~V}$ (optimized for $\mathrm{Bi}$ ) are used, the lower-energy noise ions cannot reach the reflecting region and detector. Thus, the ramped steering plates prevent many of the noise ions from reaching the detector.

With conditions optimized for continuous ion injection and the use of the ramped steering plate, detection limits were determined by the integrating oscilloscope method for four elements across the mass range; the results are shown in Table 1. No fair comparison can be made between the ramped-plate detection limits and those discussed earlier, because the rampedplate data were obtained by using continuous ion injection. Overall, detection limits are in the $0.4-2 \mathrm{ppb}$ range; $\mathrm{Li}$ is the worst.

The mass bias is not as great in these new values as in the other values in Table 1. However, further improvement is possible. The ramping circuit utilized here is not optimal, especially at the ends of the mass range - a fact that is evident from the detection limit for $\mathrm{Li}$. The steering-plate potential is linear with mass [10]; however, the flight time is proportional to the square root of mass. Consequently, a linear ramp is not really optimal for this application, and the elements at the end of the mass range are affected the most. Signals for $\mathrm{Bi}$ and $\mathrm{Li}$ are compromised the most and would be most improved by a better ramping circuit.

Continuous ion injection was employed with the ramping operation because there is a mass bias in the pulsed-ion-injection process that might have obscured the effect of the ramp. This bias arises from the mass- 
a

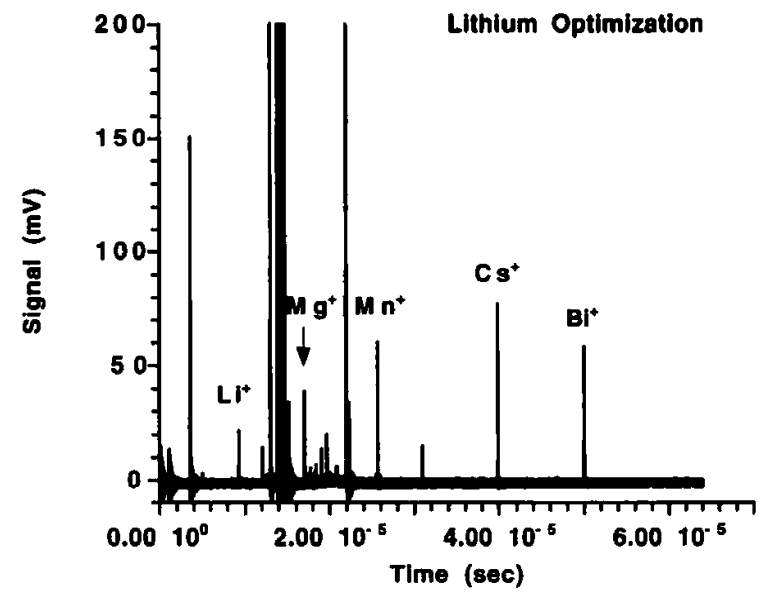

b

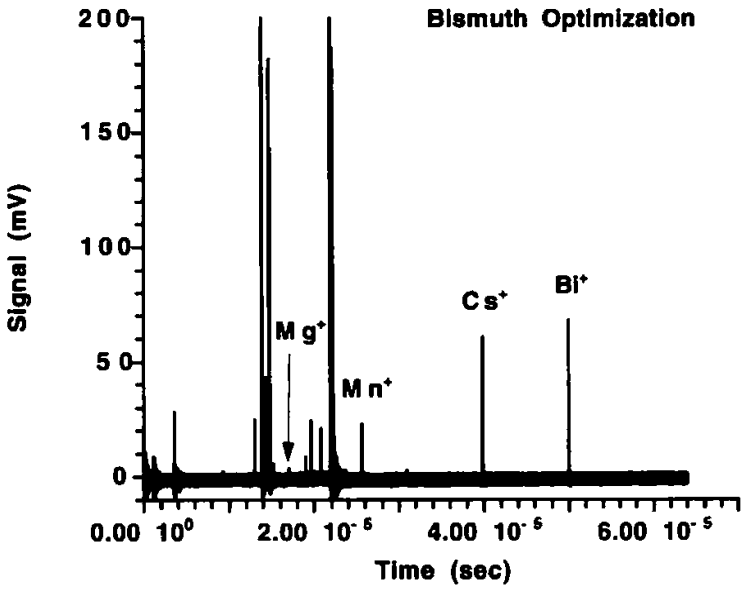

c

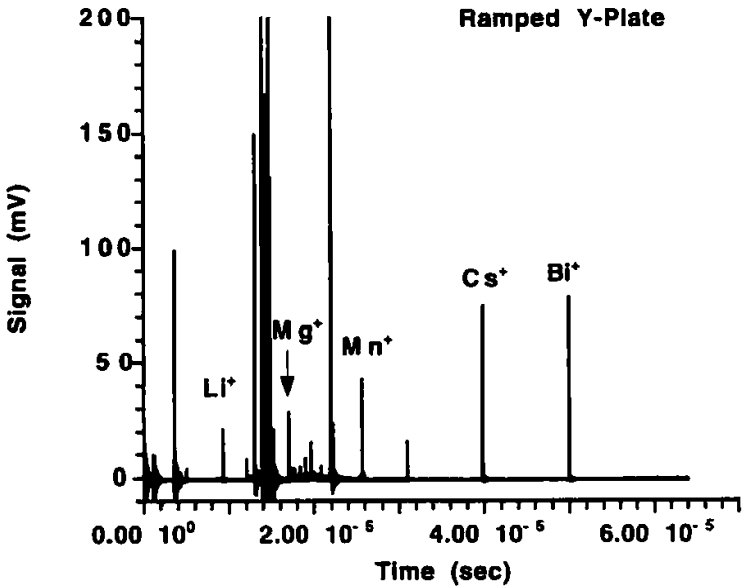

Figure 10. Spectra for 1-ppm multielement ( $\mathrm{Li}, \mathrm{Mg}, \mathrm{Mn}, \mathrm{Cs}, \mathrm{Bi}$ ) solution. Spectra for instrument optimized (a) for Li signal and (b) for Bi signal (both average of 1000 shots). (c) Spectrum with optimized ramp applied to the steering plate of the TOFMS (average of 1000 shots).

dependent energies in the original ion beam extracted from the ICP [17]. As a consequence, the $Q_{y}$ pole pulse amplitude [17], the dc potential on the $Q_{x}$ poles [17], and the slit potential must be adjusted with mass.

In summary, the ICP-TOFMS exhibits mass bias in detection limits and ion-optical conditions. However, the mass-dependent steering potential that is necessary in the right-angle TOFMS [10] can be implemented by ramping the voltage on the plate and optimizing ramping conditions. Although the ramp causes a slight loss in sensitivity, it produces lower noise levels by discriminating against low energy scattered ions. Further studies are required to determine the origins of mass bias in the detection limits and pulsed-ion-injection process.

\section{Conclusions}

An ICP-TOFMS has been evaluated as a tool for routine elemental analysis. The choice and quality of detection electronics in the TOFMS is vital to ensure adequate analytical performance. Overall, analog integration techniques offer the best sensitivity, precision, and dynamic range. With discriminator-gated integration the linear dynamic range of the instrument is 4-5 orders of magnitude and detection limits are in the 10-100 parts-per-trillion range for most elements, which is 10-100 times worse than in commercial quadrupole ICP mass spectrometers. However, the ICP-TOFMS enables all elements and isotopes to be determined at once. The current discriminator-gated integration system incorporates only two channels, but one could envision many similar channels to perform multielement or multiisotope analysis. Software integration of averaged spectra from a digital oscilloscope produces similar detection limits but with a six times shorter integration time than the CFD-gated integrator. The principal reason that detection limits are poorer than those from commercial instruments is the density of analyte ions in the primary beam extracted into the ICP-TOFMS, which is estimated to be 10-100 times lower than in typical quadrupole instruments.

Detection limits are disappointing for elements close to argon because of low signal levels. It seems likely that the argon-ion deflection scheme employed in the instrument affects the transmission of ions in the nearby mass range. Detection limits are better for the heavier elements, which suggests possible spacecharge effects in the optical system. Further study is needed to determine the cause of and solution to these biases. Mass-dependent steering-plate settings can be established automatically through use of a ramped TOFMS steering plate. This modification produces similar detection limits across the mass range.

Overall, the ICP-TOFMS promises to be a powerful instrument for elemental analysis of liquid samples, with detection limits that approach those of commercial instruments. With improved throughput of the primary beam and development of a fast integrating data acquisition system, the ICP-TOFMS should easily compete with quadrupole mass analyzers for the routine multielement analysis of solutions.

\section{Acknowledgment}

This research was funded in part by the National Institutes of Health through grant R01 GM48653. 
(Maryland Heights, MO) was used to control the MSD and to process the data. In all experiments, $1 \mu \mathrm{L}$ of a given solution was injected in splitless mode, the acquisition of data was started $5 \mathrm{~min}$ after injection to allow the solvent front to pass, and then the microwave-induced plasma in the CRI was ignited.

\section{Chernicals}

$\mathrm{NF}_{3}$ was obtained from Matheson (East Rutherford, $\mathrm{NJ}$ ). (Note: Although $\mathrm{NF}_{3}$ is not spontaneously reactive as is $\mathrm{F}_{2}$ or $\mathrm{HF}$, it is toxic and requires appropriate care in the laboratory.) The GC carrier gas is ultrapure helium from Air Products and Chemicals (Allentown, PA). Tris-butoxyethyl phosphate (TBOEP), tributyl phosphate (TBP), $N$-methyl- $N$-(trimethylsilyl)-trifluoroacetamide (MSTFA), and nonlabeled amino acids were purchased from Sigma Chemical Co. (St. Louis, MO). L-Phenylalanine- $d_{8}(\mathrm{D}, 98 \%)$, L-leucine- $d_{10}(\mathrm{D}$, $98 \%)$ and nitrobenzene- $d_{5}(D, 99 \%)$ were from Cambridge Isotope Laboratories (Woburn, MA). Diazepam was obtained from Hoffmann-La Roche Inc. (Nutley, NJ). p,p'-DDT [1,1-bis(4-chlorophenyl)-2,2,2-trichloroethane] was from Aldrich Chemical Co. (Milwaukee, WI). All the chemicals were used without further purification. The plasma sample from a patient who received cyclophosphamide, along with pure cyclophosphamide and 4-OH-cyclophosphamide, was provided by Larry Anderson, Clinical Pharmacology Division, Food and Drug Administration, Rockville, MD. Solvents (acetonitrile and toluene) were high-performance liquid chromatography grade from EM Science (Gibbstown, NJ).

\section{Methods}

Dependent on the analysis being done, the mass spectrometer could be set in selective ion monitoring (SIM) mode for any or all of the masses indicated below. The following reactions indicate the elements, the products, the fragment ions, and the masses at which the species are detected:

$$
\begin{aligned}
\mathrm{C} \rightarrow & \mathrm{CF}_{4}\left(\mathrm{CF}_{3}^{+}, m / z 69\right) \\
\mathrm{H} \rightarrow & \mathrm{HF}\left({ }^{1} \mathrm{HF}^{+*}, m / z 20 ;{ }^{2} \mathrm{HF}^{+*}, m / z 21\right) \\
\mathrm{O} \rightarrow & \mathrm{F}_{2} \mathrm{O}\left(\mathrm{F}_{2} \mathrm{O}^{+*}, m / z 54\right) \\
& \quad+\text { other oxygen-fluorine products } \\
\mathrm{P} \rightarrow & \mathrm{PF}_{5}\left(\mathrm{PF}_{4}^{+}, m / z 107\right) \\
\mathrm{Cl} \rightarrow & \mathrm{ClF}\left({ }^{35} \mathrm{ClF}^{+*}, m / z 54 ;{ }^{37} \mathrm{ClF}^{+*}, m / z 56\right) \\
\mathrm{S} \rightarrow & \mathrm{SF}_{6}\left(\mathrm{SF}_{5}^{+}, m / z 127\right)
\end{aligned}
$$

Phosphorus detection. A series of solutions of TBOEP from 1 to $1000 \mathrm{ng} / \mu \mathrm{L}$ was prepared in toluene with TBP as the internal standard $(10 \mathrm{ng} / \mu \mathrm{L})$. The GC column temperature was initially $90^{\circ} \mathrm{C}$ for $2 \mathrm{~min}$, then programed to $140{ }^{\circ} \mathrm{C}$ at a rate of $40{ }^{\circ} \mathrm{C} / \mathrm{min}$, then to $270{ }^{\circ} \mathrm{C}$ at $10^{\circ} \mathrm{C} / \mathrm{min}$, and held for $5 \mathrm{~min}$. The SIM program used $m / z 20,69$, and 107.

Deuterium detection. Deuterium-labeled amino acids were used as the samples. A group of solutions in water was prepared with L-phenylalanine- $d_{8}$ concentrations from $69 \mathrm{pg} / \mu \mathrm{L}$ to $69 \mathrm{ng} / \mu \mathrm{L}$ and L-leucine- $d_{10}$ and nonlabeled L-phenylalanine at constant concentrations ( 65 and $63 \mathrm{ng} / \mu \mathrm{L}$ ). These solutions were derivatized by the following procedure: $100 \mu \mathrm{L}$ of solution was dried, and $50 \mu \mathrm{L}$ of MSTFA and $50 \mu \mathrm{L}$ of dried acetonitrile were added and heated at $100{ }^{\circ} \mathrm{C}$ for 30 $\min$ in a sealed reaction vial. The GC column was set at $70^{\circ} \mathrm{C}$ for $2 \mathrm{~min}$, programed to $100^{\circ} \mathrm{C}$ at a rate of 30 ${ }^{\circ} \mathrm{C} / \mathrm{min}$ and held for $1 \mathrm{~min}$, then programed again to $200{ }^{\circ} \mathrm{C}$ at $15{ }^{\circ} \mathrm{C} / \mathrm{min}$, and held for $5 \mathrm{~min}$. SIM mode used $m / z 20,21$, and 69 .

Sulfur detection. L-Methionine solutions were prepared in water at concentrations from $66 \mathrm{pg} / \mu \mathrm{L}$ to 66 $\mathrm{ng} / \mu \mathrm{L}$ with L-cysteine as the standard $(24.5 \mathrm{ng} / \mu \mathrm{L})$. The solutions were derivatized as described in the foregoing text. The GC column was set at $70{ }^{\circ} \mathrm{C}$ for 2 min, programed to $130{ }^{\circ} \mathrm{C}$ at a rate of $40^{\circ} \mathrm{C} / \mathrm{min}$, held for $3 \mathrm{~min}$, programed again to $150{ }^{\circ} \mathrm{C}$ at $2.5^{\circ} \mathrm{C} / \mathrm{min}$, then to $250^{\circ} \mathrm{C}$ at $20^{\circ} \mathrm{C} / \mathrm{min}$, and held for $1 \mathrm{~min}$. The MSD was set in SIM mode with $m / z 69$ and 127 .

Chlorine detection. A series of diazepam solutions was prepared in toluene from 0.68 to $680 \mathrm{ng} / \mu \mathrm{L}$ with DDT as the internal standard $(7.2 \mathrm{ng} / \mu \mathrm{L})$. The initial GC temperature was set at $70^{\circ} \mathrm{C}$ for $2 \mathrm{~min}$, programed to $210^{\circ} \mathrm{C}$ at $30^{\circ} \mathrm{C} / \mathrm{min}$, then to 250 at $10^{\circ} \mathrm{C} / \mathrm{min}$, and held for $5 \mathrm{~min}$. The MSD was set in SIM mode with $m / z 20,54,56$, and 69 .

A mixture of eight compounds was used to demonstrate the simultaneous and selective detection of all these targeted species: nitrobenzene- $d_{5}$, TBP, caffeine, thiopental, methyl palmitate, methyl stearate, TBOEP, and diazepam. The concentrations of these compounds were not precisely measured, but were about 100,10 , $150,100,150,300,30$, and $150 \mathrm{ng} / \mu \mathrm{L}$, respectively, following their evaporation and reconstitution in toluene. Amino acids were not used because they required derivatization and increased the complexity of the sample. The GC temperature was set at $70^{\circ} \mathrm{C}$ for $2 \mathrm{~min}$, programed to $120^{\circ} \mathrm{C}$ at $30^{\circ} \mathrm{C} / \mathrm{min}$, then to 250 ${ }^{\circ} \mathrm{C}$ at $10^{\circ} \mathrm{C} / \mathrm{min}$, and held for $5 \mathrm{~min}$. The mass spectrometer was set in SIM mode with $m / z 20,21,56,69$, 107 , and 127.

The plasma sample from the patient who received cyclophosphamide was processed in the Food and Drug Administration laboratories via the following scheme. Reactive metabolites were trapped by collecting blood samples in tubes that contained $2 \mathrm{~mL}$ of acetonitrile, 1 $\mathrm{mL}$ of methanol, $1 \mathrm{~mL}$ of $2-\mathrm{M}$ monobasic sodium 
phosphate ( $\mathrm{pH} 4.6$ ), and $250 \mu \mathrm{L}$ of a methanol solution that contained O-pentafluorobenzyl-hydroxylamine $\mathrm{HCl}(50 \mathrm{mg} / \mathrm{mL})$ and the O-pentafluorobenzyloxime derivative of ${ }^{2} \mathrm{H}_{4}$-aldophosphamide $(16 \mu \mathrm{g} / \mathrm{mL})$. After at least $3 \mathrm{~h}$, the samples were centrifuged and the supernatant was removed and mixed with $1 \mathrm{~mL}$ of $\mathrm{CHCl}_{3}$. After vortexing, $1.6 \mathrm{~mL}$ of the lower organic layer was removed and evaporated, and the residue was silylated at room temperature for $1 \mathrm{~h}$ by addition of $250 \mu \mathrm{L}$ of acetonitrile and $60 \mu \mathrm{L}$ of $N$-(t-butyldimethylsilyl)- $N$-methyltrifluoroacetamide.

\section{Results and Discussion}

\section{Chemistry}

Once an analyte from a chromatographic column enters a CRI carried in helium and mixes with the reactant gas, both analyte and reactant gas are decomposed into atoms by a microwave-powered plasma. As atoms leave the reaction chamber, they recombine to form small molecules in accordance with their chemical thermodynamic characteristics. A mass spectrometer in SIM mode serves as the detector to selectively measure the newly formed molecules. The mass spectrometer response provides both qualitative (which elements or isotopes are present) and quantitative (how much of that element or isotope is present) information.

Prior to this research, the CRIMS reactant gases studied could be classified into two categories based on their chemical characteristics: oxidative or reductive. Oxidative reactant gases are $\mathrm{O}_{2}, \mathrm{CO}_{2}$, and $\mathrm{SO}_{2}$ and reductive gases are $\mathrm{H}_{2}, \mathrm{HCl}, \mathrm{NH}_{3}$, and $\mathrm{N}_{2}$. Our original strategy for generation of a volatile, stable CRIMS product that contained phosphorus was based on the observation by Matsumoto et al. [18] that $\mathrm{PH}_{3}$ could be generated from phosphate in a reductive environment. Efforts to use these gases for the selective detection of phosphorus-containing compounds were not successful.

A new chemical strategy that uses a fluorine-rich environment in the reaction interface was evaluated. Initially, $\mathrm{SF}_{6}$ was used as the fluorine source. With $\mathrm{SF}_{6}$ as the reactant gas, phosphorus was converted into $\mathrm{PF}_{5}$ and could be selectively detected at $m / z 107\left(\mathrm{PF}_{4}^{+}\right)$, the most abundant peak in the $\mathrm{PF}_{5}$ mass spectrum. This was the first successful CRIMS experiment to selectively detect phosphorus.

However, $\mathrm{SF}_{6}$ was not a good reactant gas for several reasons. First, the P-selective detection channel, $m / z$ 107, could be interfered with by ${ }^{34} \mathrm{~S}^{16} \mathrm{OF}_{3}^{+}$, a CRIMS product of $\mathrm{SF}_{6}$ and $\mathrm{O}_{2}$. In addition, $\mathrm{SF}_{6}$ is inherently very stable and does not seem to generate a highly reactive fluorinating environment. It did, however, prove the concept that a CRIMS chemistry with fluorine could yield a P-selective species. We wanted to establish this feasibility with an inexpensive reac- tant gas before proceeding to $\mathrm{NF}_{3}$, which sells for more than $\$ 2000$ for a 3-lb tank.

We tried $\mathrm{NF}_{3}$ and it was a success. The chemistry for $\mathrm{NF}_{3}$ is similar to that of $\mathrm{SF}_{6}$ except that $\mathrm{NF}_{3}$ does not reform itself readily, but yields $\mathrm{N}_{2}$ and $F_{2}$ as products to a major extent. $\mathrm{SF}_{6}$ preferentially recombined. With abundant fluorine, not only did $\mathrm{PF}_{5}$ form readily, but other species were noted in accordance with the reactions listed in the Methods section.

Not only does this fluorine-generating scheme provide $\mathrm{P}$-selective detection, it is good for several other elements such as $\mathrm{Cl}$ and $\mathrm{S}$ as well as the isotopes of hydrogen. $\mathrm{CIF}$ is the CRIMS product for chlorine from organic compounds. Both $\mathrm{m} / z 54$ and $\mathrm{m} / z 56$ can be used as the detection channel. However, $m / z 54$ could be interfered with by $\mathrm{SF}_{4}^{++}$, which is part of the mass spectrum of $\mathrm{SF}_{6}$, a CRIMS product when sulfur is present. Another concern was that $\mathrm{F}_{2} \mathrm{O}^{+\cdot}$ at $\mathrm{m} / \mathrm{z} 54$ could be a CRIMS product of oxygen, although we did not note any peak in the $\mathrm{m} / \mathrm{z} 54$ channel in our experiments with oxygen-containing compounds. It would appear that if there are no sulfur-containing compounds present, $m / z 54$ could be used because it provides a threefold more abundant species than the $m / z 56$ channel. The selective detection channel for sulfur-containing compounds is $m / z 127\left(\mathrm{SF}_{5}^{+}\right)$, the base peak in the mass spectrum of $\mathrm{SF}_{6} . \mathrm{SF}_{6}$ is the primary CRIMS product of sulfur in the fluorinating environment.

Hydrogen fluoride appears as the main CRIMS product of hydrogen atoms from organic compounds. We find that $m / z 20$ and 21 can be used to selectively measure $\mathrm{H}$ and $\mathrm{D}$. Although $\mathrm{m} / z 20$ provides a general detection channel for unlabeled organic compounds, $m / z 21$ is selective for deuterium-containing compounds. Our previous scheme for selectively monitoring deuterium used $\mathrm{H}_{2}$ as the reactant gas and monitored $\mathrm{HD}$ at $m / z 3.022$ with a resolving power of $2000[2,11]$. Its two disadvantages were that it required a high resolution mass spectrometer and we could neither monitor hydrogen nor measure $D / H$ ratios because of the large amount of $\mathrm{H}_{2}$ that was used as the reactant gas. The procedure described here avoids both of these problems.

$\mathrm{CF}_{3}^{+}(m / z$ 69) can be used as a general carbon detection channel. However, the baseline at this mass is high and variable, especially when temperature programs are used. There were many possible carbon sources including GC column coating, bleeding, ferrules, transfer line, and so forth. The recommended measures to reduce this background are to passivate the system by using a higher than normal pressure and temperature of $\mathrm{NF}_{3}$ and to remove obvious sources of hydrocarbonlike materials and replace them with metal or Teflon . Further work to accomplish this is planned. Fortunately, $\mathrm{HF}(m / z 20)$ could be used as an alternative general detection channel. In this research, we always collected both $m / z 20$ and 69 , and the $m / z 20$ channel usually provided better chromatograms of or- 
ganic compounds. Although we did not demonstrate it, monitoring $\mathrm{m} / \mathrm{z} 70$ should provide a channel for ${ }^{13} \mathrm{C}$ detection.

\section{Sensitivity and Dynamic Range}

Phosphorus. To determine the sensitivity and dynamic range, a series of TBOEP solutions in toluene were used. The ion at $m / z 107$ was used as the selective channel. With an integration time of $300 \mathrm{~ms}$, a detection limit of $1 \mathrm{ng}$ of TBOEP was achieved with a signal-to-noise ratio $(\mathrm{S} / \mathrm{N})$ greater than 3 . With an $\sim 8$-s peak width at half-height, this equates to 10 $\mathrm{pg} / \mathrm{s}$ for elemental phosphorus detection. As discussed below, this level of sensitivity is at least an order of magnitude higher than would be expected with our best CRIMS instrumentation. The linear dynamic range is at least 3 orders of magnitude (Figure 1a), and a correlation coefficient $\left(R^{2}\right)$ of 0.997 was obtained. Reproducibility was determined by repeated injection of a sample that contained $100 \mathrm{ng} / \mu \mathrm{L}$ of both TBOEP and TBP. For the area ratio of the two components, a relative standard deviation (RSD) of $3.2 \%$ was obtained with $n=5$.

Deuterium. Phenylalanine- $d_{8}$ and leucine- $d_{10}$ were used to determine the sensitivity and linear dynamic range. The results show that the linear dynamic range is more than 2 orders of magnitude with a correlation coefficient of 0.994 (Figure 1b). Reproducibility experi- a
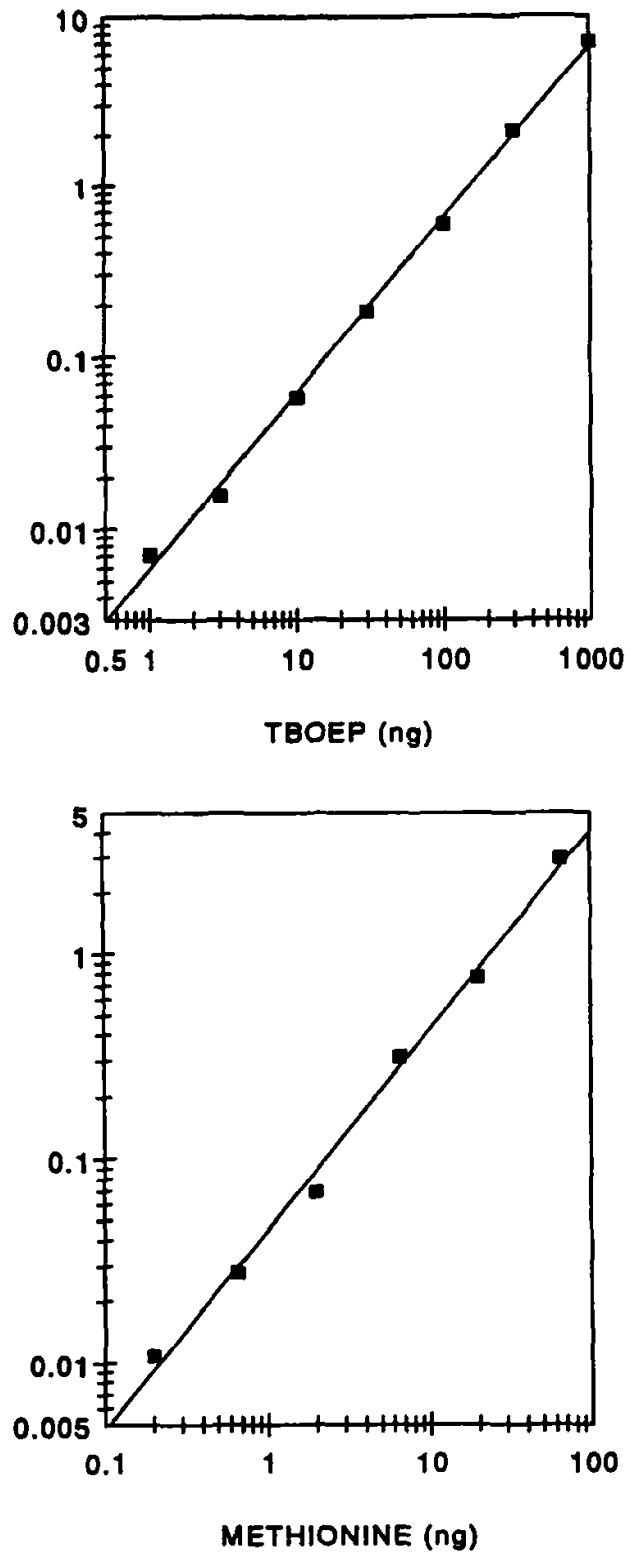

b

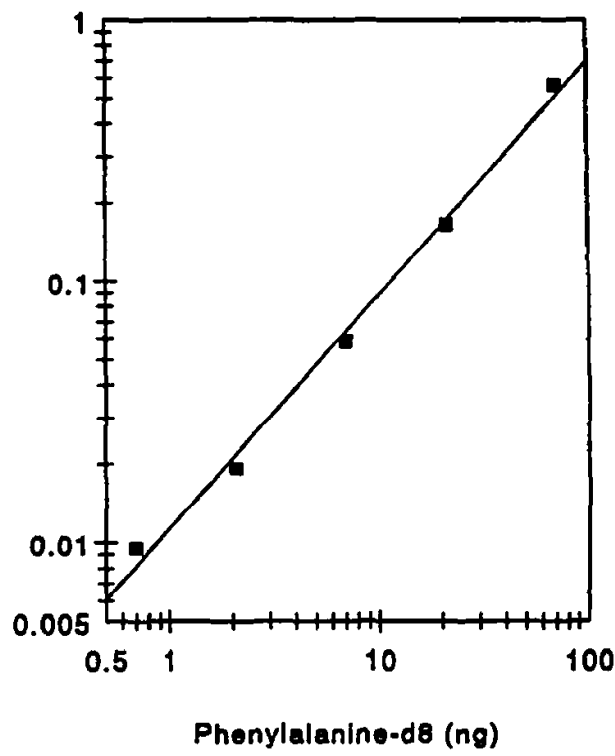

d

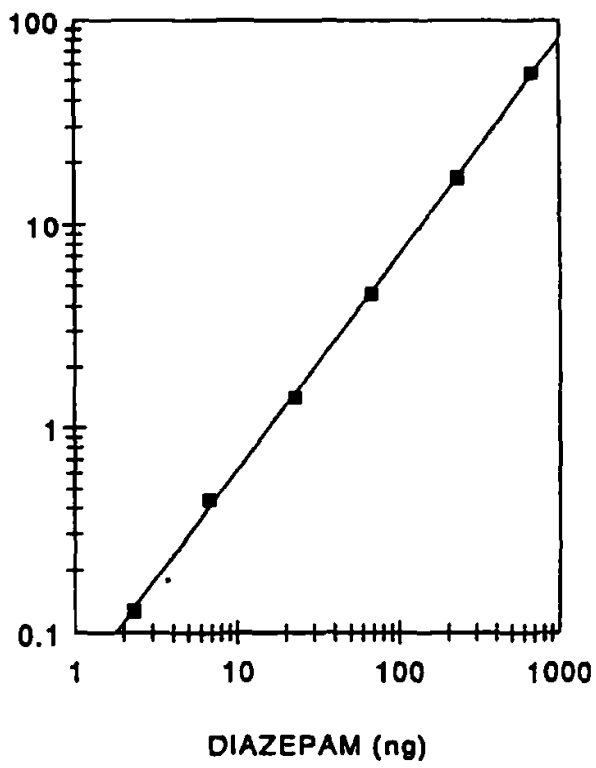

Figure 1. Linearity and dynamic range for $\mathrm{P}, \mathrm{D}, \mathrm{S}$, and $\mathrm{Cl}$ selective detection. (a) Sample $=\mathrm{TBOEP}$, standard $=\mathrm{TBP}$; (b) sample $=$ phenylalanine- $d_{8}$, standard $=$ leucine- $d_{10} ;$ (c) sample $=$ methionine, standard = cysteine; $(d)$ sample $=$ diazepam, standard $=p, p^{\prime}-\mathrm{DDT}$. 
ments showed an RSD of $2.9 \%(n=5)$ for the area ratio of $60 \mathrm{ng}$ of leucine- $d_{10}$ to phenylalanine- $d_{8}$ internal standard. In a separate experiment, the detection limit was found to be $60 \mathrm{pg}$ of phenylalanine- $d_{8}$ with an integration time of $300 \mathrm{~ms}$ and $\mathrm{S} / \mathrm{N}>5$.

Deuterium enrichment was studied with a group of samples that contained different amounts of $L^{-}$ phenylalanine- $d_{8}$ and a constant amount of unlabeled L-phenylalanine as their diTMS (ditrimethylsilyl) derivatives. The $\mathrm{D} / \mathrm{H}$ ratio for the CRIMS method was obtained from the peak areas in the $m / z 21$ (D) and $m / z 20(\mathrm{H})$ chromatograms. We found some nonlinearity when the experimental $\mathrm{D} / \mathrm{H}$ ratio was plotted against the "theoretical data," especially when the concentration of L-phenylalanine- $d_{8}$ was low. To examine this problem, another $\mathrm{D} / \mathrm{H}$ ratio was obtained in the "normal" gas chromatography-mass spectrometry (GC-MS) mode (with the CRIMS power turned off) by measuring the peak area ratio from the SIM chromatograms of $m / z 200$ (M-COOTMS for $-d_{8}$ ) and $m / z 192$ (M-COOTMS for $-d_{0}$ ), which are the most abundant mass spectrometry peaks of labeled and unlabeled diTMS phenylalanine. The 200/192 ratio then was converted into a $\mathrm{D} / \mathrm{H}$ ratio by considering the fraction of $\mathrm{H}$ atoms in diTMS phenylalanine- $d_{8}$. A $\log -\log$ plot of the $\mathrm{D} / \mathrm{H}$ ratios of the CRIMS mode against the ratios of the corrected normal GC-MS mode is shown in Figure 2. We found that these two methods-CRIMS and normal GC-MS-agreed closely with each other for the deuterium enrichment experiments. The correlation coefficient is 0.9961 and the slope is 0.94 . When regressed against theoretical data, the correlation coefficient was 0.9871 and the slope was 0.81 . The nonlinearity mentioned above may be due to errors in the concentrations or purity of the samples, or

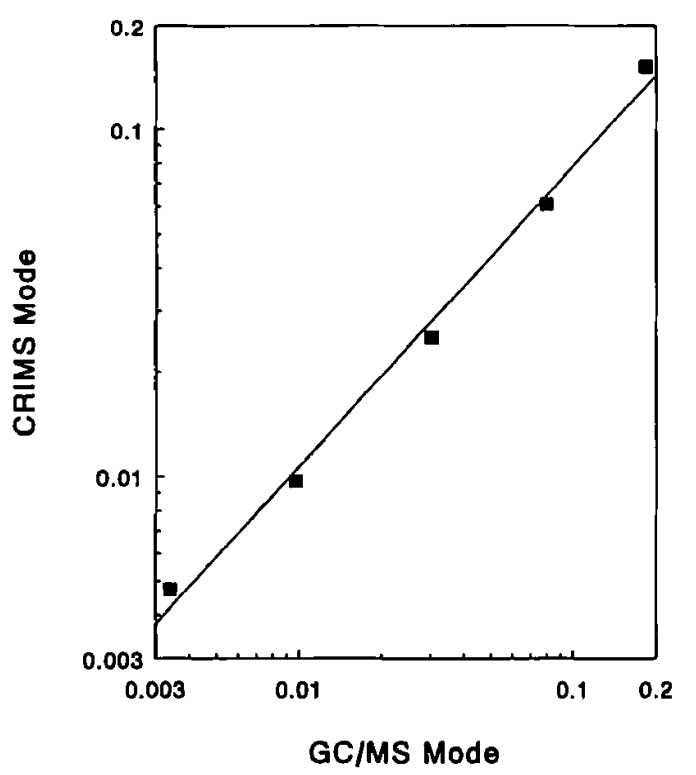

Figure 2. Comparison of the $\mathrm{D} / \mathrm{H}$ ratio obtained in CRIMS mode and in normal GC/MS mode with diTMS phenylalanine. with other instrumental problems such as ion-molecule reactions [19] or amplifier nonlinearity, but not with the CRIMS analyses.

Sulfur. A group of solutions of sulfur-containing amino acids was used for the this study. L-Methionine was used as the sample and L-cysteine was used as the internal standard. The detection was linear from 200 $\mathrm{pg}$ to $66 \mathrm{ng}$ of methionine. The 66-ng figure is not necessarily the upper limit of the linear dynamic range, although $200 \mathrm{ng}$ of L-methionine produced a deformed peak, which indicated that either the chromatography or the chemistry in the CRI was not right. A log-log plot of these data is shown in Figure 1c with a correlation coefficient of 0.992 . A detection limit of $200 \mathrm{pg}$ of L-methionine was obtained with an integration time of $400 \mathrm{~ms}$ and signal-to-noise ratio of 3 . An RSD of $4.4 \%$ $(n=5)$ was obtained with $20 \mathrm{ng}$ of L-methionine and $24 \mathrm{ng}$ of L-cysteine.

Previously, when the HP 5971A MSD was used with $\mathrm{SO}_{2}$ as the reactant gas, the detection limit was 1 ng of diazepam [17]. This is comparable with the present work with $\mathrm{NF}_{3}$ as the reactant gas, which provided a 2-ng limit for the same compound. That report [17] also included a performance comparison of the Extrel C50/400 (Extrel Corp., Pittsburgh, PA) and HP 5971A MSD under several conditions. Although the 2-ng detection limit for $\mathrm{Cl}$ does not appear as good as the 50-pg value from a previous study [9] with $\mathrm{SO}_{2}$ as the reactant gas, that result was achieved on the Extrel instrument with its special $2.1-\mathrm{MHz}$ power supply that maximizes the transmission and resolution at low mass ranges.

Chlorine. Chlorine-containing compounds also can be determined selectively. As was done previously [9], a group of diazepam solutions was prepared in toluene, with $p, p^{\prime}$-DDT as the internal standard. The ion at $m / z 56$, or ${ }^{37} \mathrm{ClF}^{+*}$, was used as the selective detection channel. The detection limit is $\mathbf{2} \mathbf{~ n g}$ of diazepam with a signal-to-noise ratio of 3 and an integration time of 300 $\mathrm{ms}$. A linear dynamic range of 3 orders of magnitude has been achieved with a correlation coefficient of 0.9996 (Figure 1d). A reproducibility test with a sample of 130-ng diazepam and 50-ng DDT showed an RSD of $3.4 \%(n=4)$.

As was true for $\mathrm{Cl}$, the detection limit reported here for sulfur-containing compounds is well above the previously reported result of $30 \mathrm{pg}$ of thiopental [8]. Those experiments used $\mathrm{HCl}$ as the reactant gas and Extrel C50/400 with its $2.1-\mathrm{MHz}$ supply as the detector. We generally believe that if the Extrel C50 is equipped with its better rf power supply, it will provide more than tenfold better sensitivity than HP 5971A MSD [14]. If this is true, then $\mathrm{NF}_{3}$ will provide detection limits below $200 \mathrm{pg}$ for chlorine- and $20 \mathrm{pg}$ for sulfur-containing compounds on the more sensitive 
mass spectrometer system. It may be that the $\mathrm{NF}_{3}$ reactions that yield $\mathrm{SF}_{6}$ generate a more readily formed and transmitted species than CIS and detection below the 30-pg level can be obtained.

\section{Selectivity}

To study the selectivity, a mixture of eight compounds that contained various elements was prepared. The ion at $m / z 20$ was used to monitor the-hydrogen contained in all the organic compounds, and $m / z 21,56$, 107 , and 127 were used to simultaneously detect deuterium-, chlorine-, phosphorus-, and sulfur-containing compounds, respectively. Figure 3 shows the chromatograms of these channels, all of which appear to be highly selective.

\section{Application to Detection of Phosphorus-Containing Drugs}

Cyclophosphamide is an anticancer drug that contains one phosphorus and two chlorine atoms in its structure. With $\mathrm{NF}_{3}$ as the reactant gas, CRIMS can provide simultaneous detection of $\mathrm{P}$ and $\mathrm{Cl}$; thus, it seems to

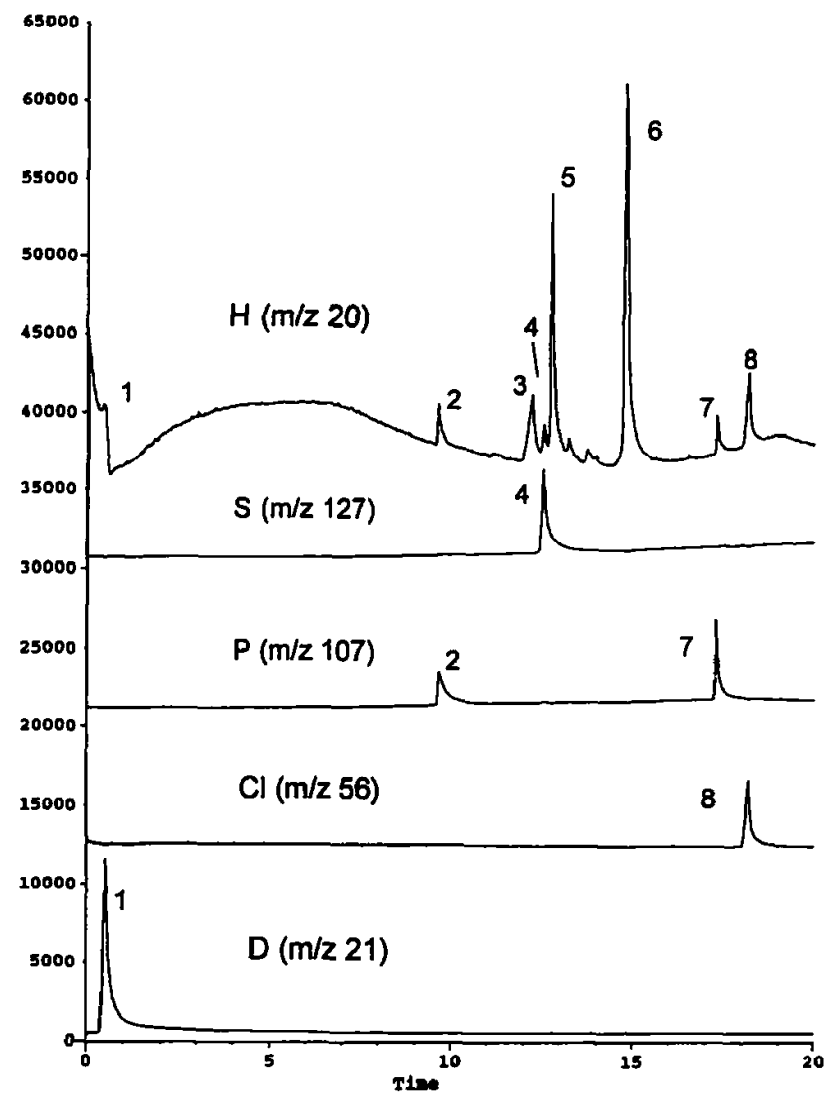

Figure 3. Chromatograms from a test mixture. The chromatograms that show $m / z 21,56,107$, and 127 were magnified 2, 15,7 , and 4 times, respectively, compared to the $m / z 20$ trace for which the intensity scale is correct. The peak identities are $1=$ nitrobenzene- $d_{5}, 2=$ TBP, $3=$ caffeine, $4=$ thiopental, $5=$ methyl palmitate, $6=$ methyl stearate, $7=$ TBOEP, and $8=$ diazepam. be an ideal choice for the analysis of this drug and its metabolites. A plasma sample from a patient who received cyclophosphamide was analyzed for both phosphorus and chlorine content with CRIMS. The results are shown in Figure 4. General detection $(\mathrm{H})$ is shown in the upper chromatogram, phosphorusselective detection is in the middle, and chlorine detection is the bottom chromatogram. Although the $\mathrm{H}$ channel showed a complex chromatogram, only six peaks were seen in the P-selective channel, and five peaks appeared in the $\mathrm{Cl}$-selective channel. All but the first peak in the phosphorus channel were confirmed as cyclophosphamide related by the response in the chlorine channel.

The first peak in the phosphorus channel was phosphate silylated with three $t$-butyldimethylsilyl (TBDMS) groups, as confirmed by its mass spectrum. A TBDMS-derivatized cyclophosphamide standard solution showed three peaks, which matched the retention times of peaks 2,3 , and 5 in the sample chromatogram. Peak 5 was found to be TBDMScyclophosphamide and peak 3 was underivatized cyclophosphamide. Peak 2 showed an area ratio of the $\mathrm{Cl}$ to the $\mathrm{P}$ channel half the value of other two peaks, which indicated there was a loss of one of the two chlorine atoms in cyclophosphamide. The mass spec-

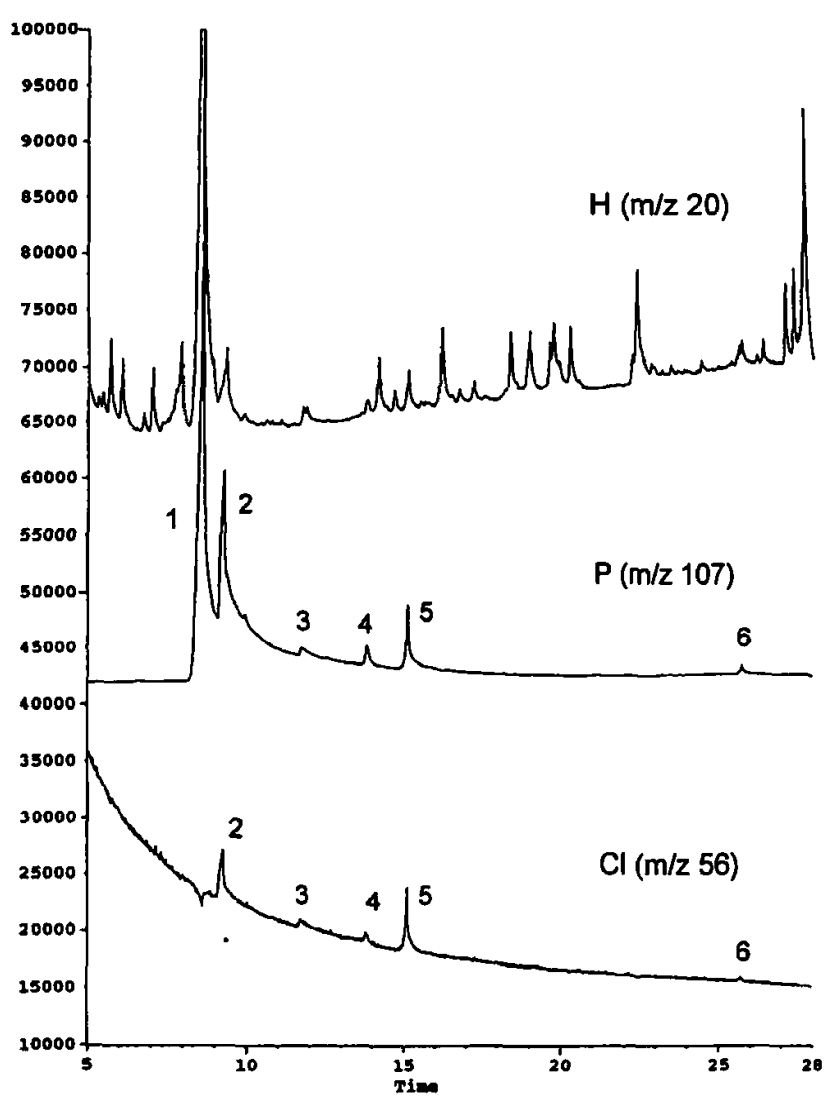

Figure 4. Chromatograms of a plasma sample that contains cyclophosphamide and its metabolites. The $\mathrm{m} / z 107$ and 56 chromatograms are magnified by 2.5 and 25 times compared to the $m / z 20$ chromatogram for which the intensity axis is correct. The peaks are identified in the text. 
trum of this peak suggested that one of the two chloroethyl arms was missing.

A possible explanation is that some cyclophosphamide was decomposed in the GC injector; no further investigation was done to confirm this assumption. Peaks 4 and 6 appeared at the same retention times as the two peaks from the 4-hydroxycyclophosphamide standard. Peak 4 also showed a peak area ratio of $\mathrm{Cl}$ to $\mathrm{P}$ of only half the other peaks, thereby suggesting a $\mathrm{Cl}$ loss in its structure also.

The experimental results indicate that even for a complicated, biologically derived sample, CRIMS with $\mathrm{NF}_{3}$ provides selective detection for compounds that contain $\mathrm{P}$ and $\mathrm{Cl}$. Such drugs fit into our definition of "intrinsically labeled" [12], and therefore can simplify metabolism studies because the special synthesis to incorporate "extrinsic" isotopic labels in the drug would be unnecessary.

\section{System Performance}

The most significant drawback of the use of $\mathrm{NF}_{3}$ as the reactant gas is that the electron multiplier (EM) life was reduced rapidly in the HP 5971A MSD system. The EM had to be changed every two to three months to maintain acceptable sensitivity. The explanation is that the $\mathrm{F}_{2}$ that is formed in the CRI from $\mathrm{NF}_{3}$ is very reactive toward the conductive surface of the multipliers. In addition, some etching was found in the fused silica transfer line between the CRIMS tube and the mass spectrometer. When the CRIMS plasma is on, $\mathrm{F}_{2}$ could continuously attack the EM surface and the life of EM would be shortened. This phenomenon is particularly serious on a system without differential pumping, which has no barrier between the ion source and the analyzer.

We tried different types of electron multipliers: a glass-based EM from Galileo Electro-Optics (Sturbridge, MA), a ceramic-channel EM from $K$ \& M Electronics (West Springfield, MA), and a metal EM from ETP Scientific (Auburn, MA). All of these EMs showed short lifetimes, and there was no meaningful variation in the speed of degradation. A separate test that used $\mathrm{NF}_{3}$ as the reactant gas was conducted on a differentially pumped mass spectrometry system-our DuPont 21-492 - with a glass-based Galileo electron multiplier. The instrument was operated in its usual manner and no noticeable change was observed over a time frame in which degradation of sensitivity was substantial in the MSD. Routine CRMMS work has continued on the 21-492 for weeks with $\mathrm{NF}_{3}$ as the reactant gas, and the sensitivity has still not shown any significant loss. Obviously, differential pumping greatly reduces the deleterious effects of $\mathrm{NF}_{3}$ CRIMS on electron multipliers.

\section{Conclusions}

$\mathrm{NF}_{3}$ represents a new concept of reactant gases for CRIMS. By providing a fluorinating reaction environment, it permits the selective and simultaneous detection of phosphorus, as well as deuterium, chlorine, and sulfur. The methods are sensitive, linear, and reproducible. As the array of element and isotope selective detection capabilities of CRIMS grows, so should its applications.

\section{Acknowledgments}

This research was supported by United States Public Health Service Grant 5-R01-GM36143. We thank Larry Anderson of the Food and Drug Administration for the cyclophosphamide sample and much help in its analysis. This work was presented, in part, at the 42nd Annual Meeting of the American Society for Mass Spectrometry, Chicago, IL, June 1994.

\section{References}

1. Markey, S. P.; Abramson, F. P. Anal. Chem. 1982, 54, 2375-2376.

2. Chace, D. H.; Abramson, F. P. Anal. Chem.' 1989, 61, 2724-2730.

3. Morré, J. T.; Moini, M. Biol. Mass Spectrom. 1992, 21, 693-699.

4. Chace, D. H.; Abramson, F. P. Biomed. Environ. Mass Spectrom. 1990, 19, 117-122.

5. Chace, D. H.; Abramson, F. P. J. Chromatogr. 1990, 527, 1-10.

6. Chace, D. H.; Abramson, F. P. In Synthesis and Applications of Isotopically Labelled Compounds, 1988; Baillie, T. A.; Jones, J. R., Eds.; Elsevier: Amsterdam, 1989; p 253.

7. Abramson, F. P.; Markey, S. P. Biomed. Environ. Mass Spectrom. 1986, 13, 411-415.

8. Moini, M.; Chace, D. H.; Abramson, F. P. I. Am. Soc. Mass Spectrom. 1991, 2, 250-255.

9. Song, H.; Abramson, F. P. Anal. Chem. 1993, 65, 447-450.

10. Kusmierz, J. J.; Abramson, F. P. Biol. Mass Spectrom. 1993, 22, 537-543.

11. Teffera, Y.; Abramson, F. P.; McLean, M.; Vestal, M. J. Chromatogr. Biomed. Appl. 1993, 620, 89-96.

12. Song, H.; Abramson, F. P. Drug Metab. Disp. 1993, 21, 868-873.

13. Li, G.; Moini, M. Proceedings of the 42nd ASMS Conference on Mass Spectrometry; 1994; p 293.

14. Teffera, Y.; Abramson, F. Biol. Mass Spectrom. 1994, 24, 776-783.

15. O'Brien, M. J. In Modern Practice of Gas Chromatography; Grob, R. L., Ed.; John Wiley \& Sons, New York, 1985; p 272.

16. Quimby, B. D; Sullivan, J. J. Anal. Chem. 1990, 62, 1027-1034.

17. Song, H.; Kusmierz, J.; Abramson, F.; McLean, M. J. Am. Soc. Mass Spectrom. 1994, 8, 765-771.

18. Matsumoto, K.; Fujiwara, K.; Fuwa, K. Anal. Chem. 1983, 55 , 1665-1668.

19. Patterson, B. W.; Wolfe, R. R. Biol. Mass Spectrom. 1993, 22, 481-486. 